Document downloaded from:

http://hdl.handle.net/10251/53703

This paper must be cited as:

Díaz-Madroñero Boluda, FM.; Mula, J.; Peidro Payá, D. (2014). A review of discrete-time optimization models for tactical production planning. International Journal of Production Research. 52(17):5171-5205. doi:10.1080/00207543.2014.899721

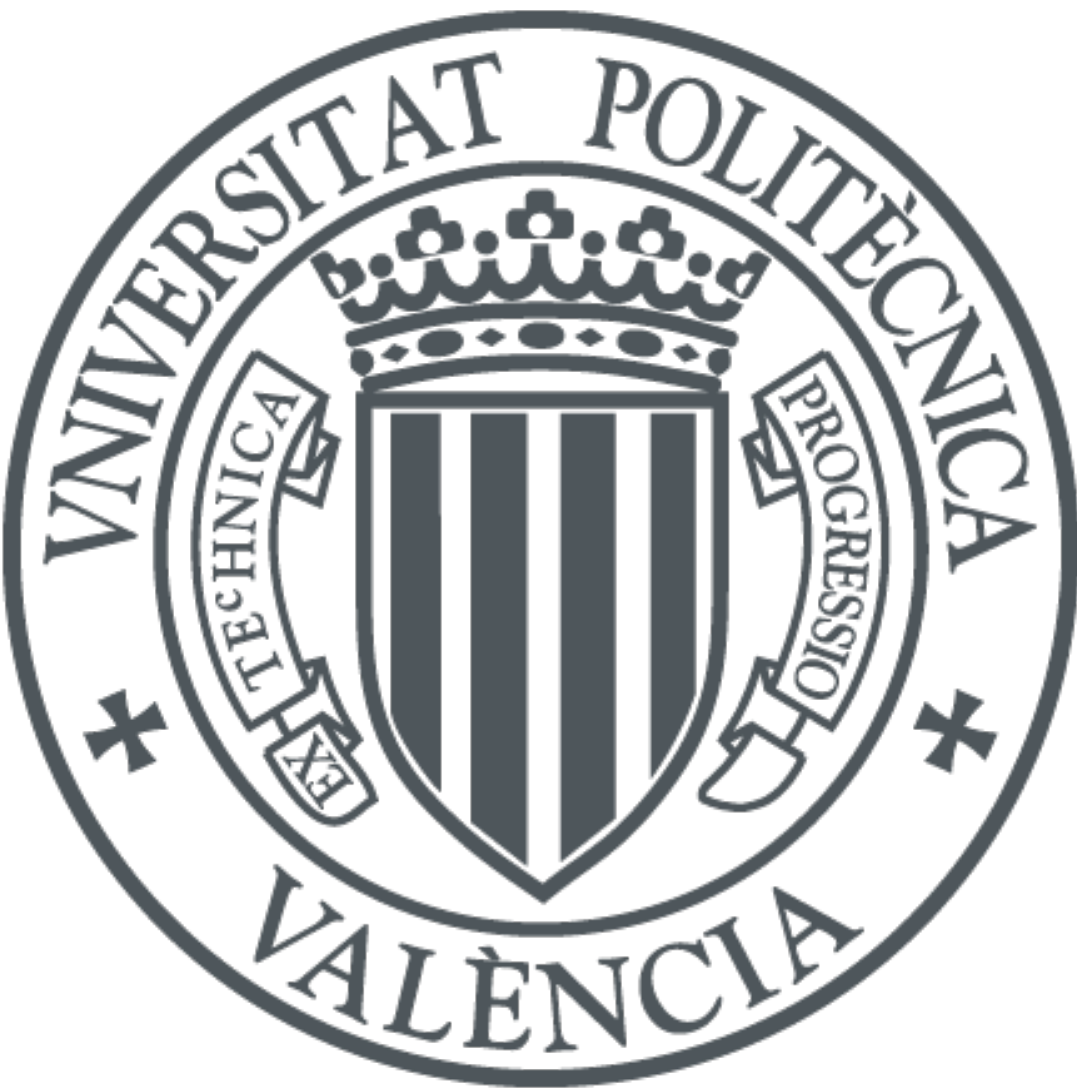

The final publication is available at

http://doi.org/10.1080/00207543.2014.899721

Copyright Taylor \& Francis: STM, Behavioural Science and Public Health Titles

Additional Information

This is an Accepted Manuscript of an article published in International Journal of Production Research on 27 Mar 2014, available online: http://doi.org/10.1080/00207543.2014.899721 
See discussions, stats, and author profiles for this publication at: https://www.researchgate.net/publication/264626305

\section{A review of discrete-time optimization models for tactical production planning}

Article in International Journal of Production Research · September 2014

DOI: 10.1080/00207543.2014.899721

\section{CITATIONS}

36

3 authors, including:

Manuel Díaz-Madroñero

Universitat Politècnica de València

71 PUBLICATIONS 502 CITATIONS

SEE PROFILE
READS

729

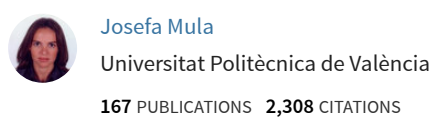

SEE PROFILE

Some of the authors of this publication are also working on these related projects:

Project Enhancing and implementing knowledge based ICT solutions within high risk and uncertain conditions for agriculture production systems View project

Project $\quad$ ICTplast View project 


\title{
A review of discrete-time optimization models for tactical production planning
}

\author{
Manuel Díaz-Madroñero, Josefa Mula*, David Peidro \\ Research Centre on Production Management and Engineering (CIGIP) \\ Universitat Politècnica de València, Spain
}

\begin{abstract}
This paper presents a review of optimization models for tactical production planning. The objective of this research is to identify streams and future research directions in this field based on the different classification criteria proposed. The major findings indicate that: (1) the most popular production planning area is master production scheduling with a big-bucket time-type period; (2) most of the considered limited resources correspond to productive resources and, to a lesser extent, to inventory capacities; (3) the consideration of backlogs, setup times, parallel machines, overtime capacities and network-type multi-site configuration stand out in terms of extensions; (4) the most widely used modeling approach is linear/integer/mixed integer linear programming solved with exact algorithms, such as branch-and-bound, in commercial MIP solvers; (5) CPLEX, C and its variants and Lindo/Lingo are the most popular development tools among solvers, programming languages and modeling languages, respectively; (6) most works perform numerical experiments with random created instances, while a small number of works were validated by real-world data from industrial firms, of which the most popular are sawmills, wood and furniture, automobile and semiconductors and electronic devices.
\end{abstract}

Keywords: Production planning; lot sizing; mathematical programming; optimization; tactical planning; discrete-time models.

\section{Introduction}

Production planning is related to managing the productive resources required to perform transformation from raw materials to final products to satisfy customers in the most efficient way (Pochet, 2001). The production planning problem can be decomposed according to the time horizons considered. Several authors, such as Anthony (1965), Salomon et al. (1991), McDonald and Karimi (1997), Min and Zhou (2002) and Gupta and Maranas (1999, 2003), among others, classify production planning problems into strategic, tactical and operational problems. Strategic planning models affect design and configuration over a time between 5 and 10 years. Tactical planning models attempt to adopt the most optimum use of the available resources by determining materials flow, inventory levels, capacity utilization, the amounts to produce and maintenance activities, with a planning horizon from one or several months to 2 years. Tactical planning assumes that the system design and configuration is given. Operational planning models are related to the detailed scheduling definition, sequencing, lot sizes, assigning loads and vehicle routes, etc. Operational models use time periods which last between one and two weeks.

*Corresponding author: Josefa Mula, Escuela Politécnica Superior de Alcoy, Plaza Ferrándiz y Carbonell, 2, 03801, Alcoy (Alicante), SPAIN. Tel.: + 34966528423. Fax: + 34966528585. E-mail address: fcodiama@cigip.upv.es, fmula@cigip.upv.es, dapeipa@cigip.upv.es. 
Although the scientific literature based on the tactical production planning concept is vast, the main motivation of this paper is to collect, classify and overview scientific articles from the last years. Other similar reviews do not address this time window, but other previous reviews on lotsizing models (Brahimi et al., 2006b; Buschkühl et al., 2010; Comelli et al., 2008; Karimi et al., 2003; Quadt and Kuhn, 2008), production planning models under uncertainty (Aloulou et al. 2013; Dolgui \& Prodhon 2007; Dolgui et al. 2013; Grosfeld-Nir and Gerchak 2004; Koh et al. 2002; Mula et al. 2006, Yang et al. 2007), supply chain planning models under uncertainty (Ko et al. 2010; Peidro et al., 2009) and mathematical programming models for supply chain production and transport planning (Mula et al., 2010a) do.

Papers were selected based to be included in this survey on the following main criteria: (i) mathematical programming models or quantitative approaches; (ii) tactical problems; (iii) discrete-time models. We briefly describe each paper, but we do not describe or formulate the models considered in detail. This work intends to provide the reader with a starting point to investigate the literature on optimization models for tactical production planning problems. The main contributions of this paper are to (i) review the literature; (ii) classify the literature based on the problem type, aim, number of products, time period, nature of demand, capacities constraints, extensions, modeling approach, solution approach, development tool, application, limitations and benefits; (iii) identify current trends and future research directions.

The remainder of the paper consists of four other sections. The next section introduces the review methodology. Section 3 describes the classification criteria of the reviewed papers. Section 4 presents the limitations and discussion of the present study. Finally, the last section provides the conclusions and directions for future research.

\section{References collection methodology}

The search for published production planning articles was performed using the Web of Knowledge platform from January 2006. The following search criteria were applied to the topic field of this web search engine: lot sizing, production planning, tactical planning, master planning, operations planning, supply chain planning, material requirement planning, manufacturing resource planning, aggregate planning, hierarchical production planning, procurement planning, replenishment planning. From the references obtained, and after performing a reviewing process of the abstracts, approximately 600 references were selected. An additional filter, based on the journal in which each reference is published, was applied to this group. Barman et al.'s (2001) ranking was considered, which is a collection of internationally recognized production and operations research and management journals, and it was previously applied in the works of Chaudhry and Luo (2005) and Wong and Lai (2011). Barman et al.'s (2001) ranking was also completed with those journals rated at the 3rd and 4th levels from the ABS Academic Journal Quality Guide in the Operations, Technology and Management, and Operations Research and Management Science subjects. It is important to highlight that we are focused on tactical planning optimization models, thus a new group of 342 references was formed, from which those articles which focus only on strategic planning approaches (e.g., supply chain design, plant location, among others), operational decision level applications (e.g., production scheduling), non quantitative approaches, continuous-time or non discrete models and non optimization models were excluded. Having completed this process, 250 references were reviewed (Table 1 ).

As shown in Table 1, one group of three journals represented $56.40 \%$ of the references included in this work, these being: International Journal of Production Research (50 references), European Journal of Operational Research (47 references) and International Journal of Production Economics (44 references). They were followed by Computers \& Operations Research (24 references) and Computers \& Industrial Engineering (15 references), which 
together account for the $15.60 \%$ of the reviewed papers. The remaining 15 journals published $28.00 \%$ of the total considered references.

Table 1. Distribution of references according to journals

\begin{tabular}{|c|c|c|c|c|}
\hline $\begin{array}{c}\text { ABS } \\
\text { ranking }\end{array}$ & $\begin{array}{l}\text { Bartman et al's } \\
\text { (2001) ranking }\end{array}$ & Journal & References & $\%$ of total \\
\hline $\mathrm{X}$ & $\mathrm{X}$ & International Journal of Production Research & 50 & $20.00 \%$ \\
\hline $\mathrm{X}$ & $\mathrm{X}$ & European Journal of Operational Research & 47 & $18.80 \%$ \\
\hline \multirow[t]{3}{*}{$\mathrm{X}$} & $\mathrm{X}$ & International Journal of Production Economics & 44 & $17.60 \%$ \\
\hline & $\mathrm{X}$ & Computers \& Operations Research & 24 & $9.60 \%$ \\
\hline & $\mathrm{X}$ & Computers \& Industrial Engineering & 15 & $6.00 \%$ \\
\hline $\mathrm{X}$ & $\mathrm{X}$ & Journal of the Operational Research Society & 11 & $4.40 \%$ \\
\hline $\mathrm{X}$ & & Production Planning \& Control & 11 & $4.40 \%$ \\
\hline $\mathrm{X}$ & $\mathrm{X}$ & Operations Research & 10 & $4.00 \%$ \\
\hline \multirow[t]{2}{*}{$\mathrm{X}$} & & Mathematical Programming & 7 & $2.80 \%$ \\
\hline & $\mathrm{X}$ & IIE Transactions & 6 & $2.40 \%$ \\
\hline $\mathrm{X}$ & & OR Spectrum & 6 & $2.40 \%$ \\
\hline $\mathrm{X}$ & $\mathrm{X}$ & Naval Research Logistics & 5 & $2.00 \%$ \\
\hline \multirow[t]{2}{*}{$\mathrm{X}$} & & Journal of Scheduling & 4 & $1.60 \%$ \\
\hline & & Journal of Intelligent Manufacturing & 2 & $0.80 \%$ \\
\hline \multirow[t]{2}{*}{$\mathrm{X}$} & $\mathrm{X}$ & Production and Operations Management & 2 & $0.80 \%$ \\
\hline & $\mathrm{X}$ & Interfaces & 2 & $0.80 \%$ \\
\hline \multirow[t]{2}{*}{$\mathrm{X}$} & $\mathrm{X}$ & Management Science & 1 & $0.40 \%$ \\
\hline & & Supply Chain Management - An International Journal & 1 & $0.40 \%$ \\
\hline $\mathrm{X}$ & & IEEE Transactions on Engineering Management & 1 & $0.40 \%$ \\
\hline \multirow[t]{2}{*}{$\mathrm{X}$} & & Mathematics of Operations Research & 1 & $0.40 \%$ \\
\hline & & TOTAL & 250 & $100.00 \%$ \\
\hline
\end{tabular}

\section{Classification criteria}

Karimi et al. (2003) present a review of models and algorithms for capacitated lot sizing problems. According to these authors, modeling and complexity of lot sizing decisions depend on the following characteristics: planning horizon and time period, number of levels in the product structure, number of products, nature of demand, capacity or resource constraints, setup structure and inventory shortages. Quadt and Kuhn (2007) survey capacitated lot sizing problems by taking into account different extensions, such as backorders, setup carry-overs, sequence-dependent setups and parallel machines. These authors also contemplate the inclusion of setup times, multi-level product structures and overtime. Accordingly, we propose a new classification scheme with two broader categories which we call setup and demand extensions and additional extensions. In relation to setup extensions, we consider setup times and complex setup issues such as setup carry-overs, sequence-dependent setups and family setups. On the other hand, demand extensions include backlogged demand, lost sales, price-dependent demand, product substitution and time windows. Additional extensions relating to production times (overtime, undertime, subcontracting time), parallel machines and multisite, remanufacturing and quality are also contemplated. Moreover, we extend these classification criteria by adding the following categories: problem type, modeling approach, solution method, development tool, application, benefits and limitations (Mula et al., 2010a).

All the classification criteria are described as follows:

1. Problem type. This is the production planning area addressed by each article.

2. Number of products and number of levels. It refers to the number of manufactured products considered in each model and their product structures; e.g., single-item or multi-item and single-level or multi-level, respectively. 
3. Time period. The planning horizon is the time interval in which the production planning problem extends into the future. The planning horizon is divided into periods in discrete-time models.

4. Nature of demand. This consists in analyzing demand depending on its evolution over the planning horizon (e.g., static or dynamic) and if it is known (deterministic) or uncertain (modeled as stochastic, fuzzy, robust, etc.).

5. Capacities or resource constraints. It refers to the capacities of the available resources in the production system.

6. Extensions on:

a. Demand. If backlogging, shortages or lost sales, price-dependent demand, product substitutions or time windows are addressed.

b. Setups. The consideration of setup times and other characteristics relating to complex setup structures, such as sequence-dependent setups, setup carry-overs and family setup are identified.

c. Production times. This consists in non regular times related to productive resources (e.g., overtime, undertime, subcontracting times).

d. Multiple and parallel machines. If several machines exists in the production environment.

e. Multisite. It refers to the structure of the supply chain or production system, and its members.

f. Remanufacturing activities and/or quality issues related to the considered manufactured products

7. Modeling approach. It consists in the type of representation, in this case, relationship mathematics, and the aspects to be considered in the production system

8. Solution approach. These are mathematical methods and solution algorithms developed to solve the proposed models, such as exact algorithms, relaxation heuristics, metaheuristics and problem-specific heuristics.

9. Development tool. This refers to the commercial or non commercial software tools needed to implement and solve the proposed models.

10. Application. This presents the application that each model considers in terms of supporting numerical experiments or practical studies in real production contexts.

11. Benefits. They establish the main characteristics of each model that outperform the rest of the scientific literature.

12. Limitations. They identify those characteristics which limit the model from being applied to certain environments.

\subsection{Problem type}

This work, based on Mula et al. (2006), contemplates five production planning areas: Master Production Schedule (MPS) (O'Grady, 1982; Sridharan et al., 1987); Material Requirement Planning and Manufacturing Resources Planning (MRP) (Adams and Cox, 1985; Karni, 1981; Roberts and Barrar, 1992; Shorrock and Orlicky, 1978); Supply Chain Planning (SCP) (Cowdrick, 1995; Gupta et al., 2000); Aggregate Production Planning (APP) (Hax, 1975; Masud and Hwang, 1980); Hierarchical Production Planning (HPP) (Bitran et al., 1981; Hax and Meal, 1973). The MPS establishes an optimal production plan which meets customers' orders, and provides release dates and amounts of final products to manufacture by minimizing production, holding and set up costs. Typically, components production planning is dealt with by the MRP using bill of materials (BOM) and the results obtained by MPS calculations. The MPS and MRP are considered mono-site problems. However, given the increase of integration and coordination among suppliers, manufacturers and distributors, multi-site production planning or SCP has become a very important issue in recent decades. Besides, the distinction of different planning levels based on the time period and the amount of detail in the plans is known as HPP, which decomposes the global production planning problem into a number of 
subproblems that correspond to different levels of a hierarchy of plans. These subproblems can be solved in sequence so that at each level a solution imposes restrictions on the lower level problem. Lastly, the APP approach determines production, inventory and work force levels to meet fluctuating demand requirements over a planning horizon based on the existence of an aggregate item in terms of weight, volume, manufacturing time or economic value.

Of the reviewed works, 142 of them address MPS problems, followed by a group of 47 references which deal with SCP and 39 references which consider MRP problems. APP and HPP are tackled by only 15 and 7 references, respectively (Table 2).

Table 2. Problem type of the reviewed works

\begin{tabular}{lr}
\hline Problem type & References \\
\hline MPS & 142 \\
\hline SCP & 47 \\
\hline MRP & 39 \\
\hline APP & 15 \\
\hline HPP & 7 \\
\hline
\end{tabular}

\subsection{Number of products and number of levels}

The complexity of not only the production planning problem, but also its modeling, may be influenced by the number of items manufactured in the production system. In terms of number of products, we consider single-item models, in which production is planned for only a single final product, and also multi-item models which provide the production planning of several items, which may be end products, parts or components. Among the papers analyzed, 71 references address production planning for a single product, while the remaining 172 correspond to multi-item models.

Another important characteristic that can affect the complexity of production planning problems is products structure and its number of levels. In this work, we contemplate the mono-level and multi-level product structures. The former corresponds to production systems where only final products are manufactured according to the demand obtained directly from customer orders or market forecasts. In multi-level production planning models, BOM establishes a parentcomponent relationship among the items and define the number of levels in the product structure. Of the 177 references addressing production planning for multiple items, 106 references correspond to final products and 71 references consider multi-level product structures. This latter group of papers corresponds not only to MRP models, but also to SCP (27 references), APP (Jayaraman, 2006; Leung and Ng, 2007a, 2007b; Leung et al., 2007a) and HPP (Aghezzaf et al., 2011; Timm and Blecken, 2011). Table 3 summarizes the works reviewed in terms of number of products and number of levels.

Table 3. Number of products and number of levels in the product structure

\begin{tabular}{lclccc}
\hline Number of products & References & Number of levels & References & Problem type & References \\
\hline Single-item & 73 & & 106 & & \\
\hline \multirow{3}{*}{ Multi-item } & & Mono-level & MRP & 38 \\
\cline { 3 - 6 } & & & SCP & 27 \\
& \multirow{2}{*}{177} & Multi-level & & APP & 4 \\
& & & HPP & 2 \\
\hline
\end{tabular}

\subsection{Time period}


In terms of the time period terminology, multi-item production planning problems fall into the big or small bucket problems categories (Karimi et al., 2003). In small bucket models, only one type of item can be manufactured, or at most one item can be set up per period, while the time period is long enough to produce multiple items in big bucket models. Table 4 presents the time period and the product structure details of the references addressing multi-product planning problems. Among the 177 references considered which address multi-item production planning, 169 references correspond to big bucket models, 6 papers present small bucket models (Bjork and Carlsson, 2007; Gicquel et al., 2009; Kaczmarczyk, 2011; Kucukyavuz and Pochet, 2009; Lukac et al., 2008; Stadtler, 2011) and 2 references propose both small bucket and big bucket models (Transchel et al., 2011; Van Vyve and Wolsey, 2006). Moreover, among the 169 papers presenting big bucket models, 99 address mono-level production planning problems, while the 70 remaining ones consider multi-level production systems. With regard to small bucket models, only Stadtler (2011) deals with multi-level planning problems, while those references which present both small bucket and big bucket models (Transchel et al., 2011; Van Vyve and Wolsey, 2006) only consider mono-level product structures.

Table 4. Time period and number of levels in the product structure

\begin{tabular}{llc}
\hline \multicolumn{1}{c}{ Time period } & Number of levels & References \\
\hline \multirow{2}{*}{ Big-bucket } & Mono-level & 99 \\
& Multi-level & 70 \\
\hline \multirow{2}{*}{ Small-bucket } & Mono-level & 5 \\
& Multi-level & 1 \\
\hline Small-bucket and big-bucket & Mono-level & 2 \\
\hline
\end{tabular}

\subsection{Nature of demand}

Demand acts as a typical parameter of production planning models and its nature can affect their complexity. If demand levels are known exactly, demand is called deterministic. Yet if demand is not known, it can be termed uncertain. In production planning models, uncertainty is modeled by using probability distributions, fuzzy sets, stochastic approaches based on stochastic values, or several scenarios and robust approaches.

Of the references considering dynamic demand, a group of 10 papers model demand levels in accordance with selling prices (Deng and Yano, 2006; Geunes et al., 2006; Gonzalez-Ramirez et al., 2011; Guan and Philpott, 2011; Haugen et al., 2007; Huh et al., 2010; Merzifonluoglu et al., 2007; Onal and Romeijn, 2010; Smith and Martinez-Flores, 2007; van den Heuvel and Wagelmans, 2006). On the other hand, 207 references consider deterministic demand and 37 uncertain demand levels. Moreover, 6 articles propose models for both deterministic and uncertain demand patterns (Aghezzaf et al., 2011, 2010; Feng et al., 2011; Ferguson et al., 2009; Grubbstrom and Huynh, 2006b, Naeem et al., 2013). Demand uncertainty is modeled mainly by stochastic approaches (31 references), and less commonly by fuzzy approaches (Chen and Huang, 2010; Lan et al., 2011; Liang, 2007; Mula et al., 2010b, 2008; Peidro et al., 2010; Petrovic and Akoez, 2008; Torabi and Hassini, 2009; Zhang et al., 2011), robust approaches with intervals (Wei et al., 2011), probability distributions (Shi et al., 2011) and by adding noise to forecasted demand values (Genin et al., 2008). Table 5 classifies the references reviewed according to the nature of demand and the uncertainty approaches considered.

Table 5. Nature of demand and the uncertainty approaches considered

\begin{tabular}{lclc}
\hline \multicolumn{1}{c}{ Nature of demand } & References & Uncertainty approaches & References \\
\hline Deterministic & 207 & & \\
\hline \multirow{3}{*}{ Uncertain } & 37 & Stochastic & 31 \\
Deterministic + uncertain & 6 & Fuzzy & 9 \\
& & Robust with intervals & 1 \\
& & Probability distributions & 1
\end{tabular}




\subsection{Capacities or resource constraints}

A production system can be characterized by restrictions imposed by the available resources. Capacity constraints may increase the complexity of the production planning models and their resolution, but enable more realistic models. However, a group of 43 references presents uncapacitated models with no capacity constraint. In this work, we identify the constraints related to inventory limitations (48 references), supply of parts and raw materials from suppliers (24 references), productive resources such as machines and workforce (194 references) and transportation resources (21 references). Such constraints may be included in the models in isolation or in combination with others. In this sense, some of these constraints can be included in more than one capacity constraints class. For example, a model may have only production capacity constraints, while another might also include limitations related to inventory capacity constraints and/or supply from suppliers.

Table 6 shows the different combinations associated with each capacity constraint class. Most of the analyzed papers (143 references) present only capacity constraints related to productive resources. Furthermore, the combination of production capacity constraints with inventory constraints, and production capacity constraints with inventory constraints and supply constraints, are the other most common combinations, with 19 and 10 references, respectively. A group of 7 references (Gutierrez et al., 2008; Li et al., 2009a; Liu and Tu, 2008a; Liu et al., 2007; Mocquillon et al., 2011; Naeem et al., 2013; Pal et al., 2011) presents inventory constraints in isolation, while another group of 6 references (Akbalik and Penz, 2011; Baptiste et al., 2008; Rizk et al., 2008, 2006a; Wu et al., 2010; Zhang et al., 2011) addresses the production planning problem by taking into account the production and transport resources constraints.

Boudia et al. (2008), Jung et al. (2008), Almeder et al. (2009), Bard and Nananukul (2009) and Armentano et al. (2011) consider inventory, productive and transport resources constraints simultaneously, while a group of 5 references (Demirli and Yimer, 2008; Feng et al., 2010, 2008; Gunnarsson and Ronnqvist, 2008; Peidro et al., 2010) adds supply constraints to the latter combination. The remaining combinations of capacity and resource constraints appear in 4 references or less each.

Table 6. Combinations of capacity constraints classes

\begin{tabular}{clc}
\hline Capacity constraints classes & Combinations & References \\
\hline & Inventory (in isolation) & 7 \\
Inventory & Supply (in isolation) & 2 \\
(48 references) & Productive resources (in isolation) & 143 \\
& Transport resources (in isolation) & 1 \\
Supply & Inventory + Productive resources & 19 \\
(24 references) & Inventory + Transport resources & 1 \\
& Inventory + Supply + Productive resources & 10 \\
Productive resources & Inventory + Supply + Transport resources & 1 \\
(194 references) & Inventory + Productive resources + Transport resources & 5 \\
Transport resources & Inventory + Supply + Productive resources + Transport resources & 5 \\
(21 references) & Supply + Productive resources & 4 \\
& Supply + Productive resources + Transport resources & 2 \\
& Productive resources + Transport resources & 6 \\
\hline
\end{tabular}

\subsection{Extensions on:}




\section{6.a Demand}

In order to obtain production planning models that come closer to reality, in addition to considering price-dependent demand levels, several extensions related to demand are identified. For instance, the ability to meet demand through product substitution, the existence of time windows, the option of backlogs to meet demand in following periods, and modeling lost sales if demand cannot be met during the corresponding period or during the subsequent one. Table 7 presents the different extensions related to demand considered in this work. Among the reviewed references, 80 papers address the possibility of backlogging, while 30 present modeling lost sales.

There is a group of 12 papers that considers product substitutions with several approaches. A group of 4 references addresses component and subassembly substitutions by using flexible BOM (Ram et al., 2006), flexible production sequences (Begnaud et al., 2009) and alternative BOM (Lin et al., 2009; Wu et al., 2010). Substitutions for remanufactured products are considered in Li et al. (2006), Schulz (2011),Wei et al. (2011), Naeem et al. (2013) and Fazle Baki (2014), while Li et al. (2007) allow substitutions for both remanufactured products or new products with better characteristics. Conversely, Pineyro and Viera (2010) model the demand substitution of remanufactured products for new ones, and Taskin and Uenal (2009) deal with substitutions in float glass industry by using lower quality products, but with the same size and thickness as the substituted product. Lang and Domschke (2010) and Lang and Shen (2011) use the demand classes concept to incorporate substitution options into their proposed models.

Pricing decisions, hence price-dependent demand levels, are addressed by a group of 10 references (Deng and Yano, 2006; Geunes et al., 2006; Gonzalez-Ramirez et al., 2011; Guan and Philpott, 2011; Haugen et al., 2007; Huh et al., 2010; Merzifonluoglu et al., 2007; Onal and Romeijn, 2010; Smith and Martinez-Flores, 2007; van den Heuvel and Wagelmans, 2006). Moreover, the time window notion is obtained if demands levels are considered between a release (availability) date and a due date. Of the reviewed works, 7 references propose time window models. According to Brahimi et al. (2010), it is possible to distinguish between production time windows and demand time windows. A production time window is defined by subinterval $[s, t]$ of time horizon $[1, n]$, whereas demand quantity $d_{s t}$ is to be produced in interval $[s, t]$ and delivered to the client during period $t$. Conversely in a demand time window (Lee et al., 2001), delivery to the client can take place during any period in interval $[s, t]$. A group of 5 references (Absi et al., 2011; Bilgen and Guenther, 2010; Brahimi et al., 2010, 2006a; Hwang, 2007) considers production time windows, while Hwang and Jaruphongsa (2008) and Akbalik and Penz (2011) propose production planning models with demand time windows. Moreover, one of the reviewed papers (Wolsey, 2006) presents models with production and time windows separately.

Table 7. Extensions on demand

\begin{tabular}{lc}
\hline Demand extensions & References \\
\hline Backlogs & 80 \\
Lost sales & 30 \\
Substitution & 14 \\
Price-dependent levels & 10 \\
Time windows & 7 \\
\hline
\end{tabular}

\section{6.b Setups}


Generally, setup activities are included in production planning models by considering the setup costs and/or setup times which model the production changeovers between different products. The inclusion of setup times involves reducing the production capacity available per period and increases the models' complexity because they are usually modeled by introducing zero-one variables. Moreover according to Karimi et al. (2003), three other setup types of complex setups can be contemplated: setup carry-overs; sequence-dependent setups; family setups. A setup carry-over implies that the last product per period may be produced without an additional setup during the subsequent period. The inclusion of setup carry-overs reduces the setup times needed as compared to standard production planning models, which use a setup for each product produced per period. If setup parameters depend on the production sequence, then another extension relating to scheduling decisions made on production resources can be considered. The third type of complex setup structure corresponds to family setups, caused by similarities in manufacturing process.

Table 8 provides details of the number of references dealing with the considered setup extensions. Of the reviewed works, 70 include setup times, 26 consider sequence-dependent setups, and only 14 (Almada-Lobo and James, 2010; Almada-Lobo et al., 2008, 2007; Clark et al., 2010; Karimi et al., 2006; Lang and Shen, 2011; Ozturk and Ornek, 2010; Quadt and Kuhn, 2009; Sahling et al., 2009; Santos et al., 2010; Tempelmeier and Buschkuehl, 2009, 2008) and 9 references (Anily et al., 2009; Clark et al., 2010; Federgruen et al., 2007; Goren et al., 2012; Mohan et al., 2012; Mula et al., 2010b; Omar and Teo, 2007; Pastor et al., 2009; Tempelmeier and Buschkuehl, 2008; Toso et al., 2009; Xue et al., 2011) present setup carry-overs and family setups. Omar and Teo (2007), Pastor et al. (2009) and Bilgen and Guenther (2010) tackle different production planning problems with product family setup times. However, Suerie (2006) and Stadtler (2011) represent long setup times in relation to the planning period length by modeling overlapping setup times, which are typical in process industries. Moreover, Menezes et al. (2011) incorporate sequence-dependent and period-overlapping setup times. Of the 26 references addressing scheduling decisions, 19 present sequence-dependent setup times related to products, while a group of 3 references (Clark et al., 2010; Toso et al., 2009; Xue et al., 2011) includes sequence-dependent setup times which focus on family products. Bjork and Carlsson (2007), Karabuk (2008) and Gicquel et al. (2009) consider sequencedependent setups by modeling the corresponding costs in the objective function.

Table 8. Extensions on setups

\begin{tabular}{lc}
\hline Setup extensions & References \\
\hline Setup times & 70 \\
Setup sequence-dependent & 26 \\
Setup carry-over & 14 \\
Family setup & 9 \\
\hline
\end{tabular}

\section{6.c Production times}

In order to adjust the capacity usage level of productive resources, production planning models include overtime, subcontracting and undertime decisions. If during a period production capacity is less than customer demand, the decision maker may choose to produce in overtime or to outsource part of the production to meet demand without backlogs. If, however, production capacity is higher than demand, production resources may be idle for some time, which can be modeled with undertime variables. Of the reviewed works, 35 references consider overtime decisions, 19 include the possibility of subcontracting production, and only 4 references (Fandel and Stammen-Hegene, 2006; Lusa et al., 2009; Mula et al., 2008; Peidro et al., 2010) contemplate modeling idle time. Moreover, we identify that overtime and subcontracting decisions can be modeled for either the extra time or the amounts of products needed to meet customer demand. With regard to overtime decisions, 21 references opt to represent the time needed to complete the production of customers' orders in non-regular time, while 14 references 
model the amounts of products to manufacture in extra time. Besides, all the references that consider outsourcing decisions model them in terms of the amounts of products to manufacture by subcontractors.

Table 9 shows the different combinations associated with extensions on production times. Most of these works present only overtime (23 references) or subcontracting (10 references) decisions in isolation. Moreover, the combination of overtime and subcontracting production is addressed by 10 references (Erromdhani et al., 2012; Galasso et al., 2009; Jamalnia and Soukhakian, 2009; Leung et al., 2006; Liang, 2007; Merzifonluoglu et al., 2007; Mirzapour Al-e-hashem et al., 2011; Pastor et al., 2009; Timm and Blecken, 2011; Xue et al., 2011). Mula et al. (2008), Lusa et al. (2009) and Peidro et al. (2010) propose the simultaneous modeling of overtime and undertime decisions, while only Fandel and Stammen-Hegene (2006) consider undertime decisions in isolation.

Table 9. Combinations of extensions on production times

\begin{tabular}{clc}
\hline Production time extensions & Combinations & References \\
\hline Overtime & Overtime (in isolation) & 23 \\
(36 references) & Undertime (in isolation) & 1 \\
Undertime & Subcontracting (in isolation) & 10 \\
(4 references) & Overtime + undertime & 3 \\
Subcontracting & Overtime + subcontracting & 10 \\
(20 references) & & \\
\hline
\end{tabular}

\section{6.d Multiple and parallel machines}

According to Quadt and Kuhn (2007), standard production planning models can represent the existence of parallel machines by augmenting the production variables and the capacity parameters by an additional index indicating the individual machines. However, there is an alternative way of modeling parallel machines without including the additional index in the production variables. Of all the reviewed works, 34 references consider the production planning problem with multiple parallel machines. Seventeen references model parallel production systems following the approach by Quadt and Kuhn (2007), whereas 12 papers opt for the alternative formulation. Moreover, 3 references (Kaczmarczyk, 2011; Omar and Teo, 2007; Quadt and Kuhn, 2009) consider production environments with parallel identical machines (where the task's processing time is independent of the machine where it is processed). Finally, 2 references (Jozefowska and Zimniak, 2008; Mateus et al., 2010) deal with production planning problems with parallel unrelated machines (with no particular relationship between the processing times in the different machines).

We also review other approaches related to production systems with multiple machines, such as modeling multistage systems (Aghezzaf et al., 2010; Asmundsson et al., 2009; Li et al., 2006a; Rong et al., 2006; Selcuk et al., 2006; Stadtler and Sahling, 2012; Van den broecke et al., 2008), production lines (Baptiste et al., 2008; Christou and Ponis, 2009; Christou et al., 2007; Ferreira et al., 2009; Mehrotra et al., 2011; Taskin and Uenal, 2009) and groups of identical machines (Albey and Bilge, 2011). Table 10 summarizes the different approaches related to multiple and parallel machines extensions.

Table 10. Multiple and parallel machines extensions

\begin{tabular}{|c|c|c|}
\hline $\begin{array}{c}\text { Multiple and parallel machines } \\
\text { extensions }\end{array}$ & & References \\
\hline & Including the machine index in the production variables & 17 \\
\hline $\begin{array}{l}\text { Parallel machines } \\
\text { (34 references) }\end{array}$ & $\begin{array}{l}\text { Not including the machine index in the production } \\
\text { variables }\end{array}$ & 12 \\
\hline
\end{tabular}




\begin{tabular}{|c|c|}
\hline Unrelated & 2 \\
\hline Multistage systems & 7 \\
\hline Production lines & 6 \\
\hline Groups of identical machines & 1 \\
\hline
\end{tabular}

\section{6.e Multi-site}

Mono-site production planning models can be extended to multi-site ones by considering several manufacturing plants and/or by incorporating the suppliers, warehouses, distribution centers and customers constituting a supply chain. As in our previous work (Mula et al., 2010a), we propose the classification by Beamon and Chen (2001) to define the way that the organizations within the supply chain are arranged and how they relate to each other. The supply chain structure is classified into four main types: convergent, divergent, conjoined and network. Moreover, we incorporate serial supply chains formed by one actor in each echelon.

Table 11 provides details of the different configurations considered by those reviewed works addressing multi-site production planning. Most (36 references) present a network structure generally formed by manufacturing and distribution centers and demand points or customers. Twelve references propose a divergent supply chain with different structures. For example, a group of 9 references (Armentano et al., 2011; Bard and Nananukul, 2009; Boudia and Prins, 2009; Boudia et al., 2008, 2007; Chand et al., 2007; Dudek and Stadtler, 2007; Taskin and Uenal, 2009; van den Heuvel et al., 2007) considers a supply chain consisting of one production plant and several customers. Moreover, Rizk et al. $(2006,2008)$ present a divergent supply chain with one manufacturer and several distribution centers, while Tian et al. (2011) model a divergent structure with one supplier and several manufacturing centers. Those references dealing with a serial supply chain consider two members (Akbalik and Penz, 2011; Sargut and Romeijn, 2007; Selcuk et al., 2008), except Sodhi and Tang (2009), who model a supply chain formed by one supplier, a manufacturer and one customer. Convergent supply chains, with different members and only one final demand center, are addressed by Galasso et al. (2009) and Lan et al. (2011). Finally, 2 references present conjoined supply chains formed by several suppliers, one manufacturer and several customers (Zolghadri et al., 2008), and by several plants, a distribution center and several customers (Romero and Vermeulen, 2009).

In this section, we have also included those multi-site models related to APP (Leung et al., 2006; Leung et al., 2007 and Leung and Chan, 2009) and MPS (Chand et al., 2007; van den Heuvel et al., 2007; Boudia et al., 2008; Nascimento et al., 2010; Akbalik and Penz, 2010; Drechsel and Kimms, 2011 and Lan et al., 2011).

Table 11. Multi-site configurations

\begin{tabular}{lc}
\hline Multi-site configuration & References \\
\hline Network & 37 \\
Divergent & 12 \\
Serial & 4 \\
Convergent & 2 \\
Conjoined & 2 \\
\hline
\end{tabular}

\section{6.f Remanufacturing activities and/or quality issues}

In recent years, manufacturers have started to integrate remanufacturing activities into the traditional production environment. For example, remanufacturing returned products is a common practice in production plants of high valued products like computers, copiers or 
medical equipment. Thus, customers' demand can be met with new products or returned remanufactured products. Remanufacturing returned products, however, creates many new operations management problems. These include the collection of used products, dismantlement or disassembly of returned products, incorporation of remanufacturing activities into the overall production planning (Guide and Van Wassenhove, 2002), and the recycling or disposal of unused products.

Of the reviewed works, only 11 references deal with remanufacturing issues integrated into a production system, which also manufactures new products. Of these, 8 (Fazle Baki et al., 2014; Li et al., 2006; Naeem et al., 2013; Teunter et al., 2006; Li et al., 2007; Schulz, 2011; Shi et al., 2011; Zhang et al., 2012) globally consider remanufacturing tasks without modeling them individually, while Pan et al. (2009), Pineyro and Viera (2010) and Wei et al. (2011) consider only remanufacturing and disposal activities separately. Furthermore, 9 references separately deal with remanufacturing tasks from a standard production environment. Of these, 4 (Depuy et al., 2007; Jayaraman, 2006; Li et al., 2009a, 2009b) model disassembly and remanufacturing planning activities simultaneously. Nevertheless, disassembly scheduling is contemplated by Kim et al. (2006) and by Barba-Gutierrez et al. (2008) and Kim and Xirouchakis (2010), who deal with disassembly scheduling in a reverse MRP system. Moreover, Ferguson et al. (2009) and Denizel et al. (2010) propose tactical production planning models for remanufactured products by considering remanufacturing tasks generally. Table 12 details the number of references dealing with the considered remanufacturing extensions.

Table 12. Extensions on remanufacturing activities

\begin{tabular}{clc}
\hline Planning & Remanufacturing activities & References \\
\hline Manufacturing and remanufacturing & Remanufacturing (globally) & 8 \\
(11 references) & Remanufacturing + disposal & 3 \\
\hline Remanufacturing & Remanufacturing (globally) & 2 \\
(9 references) & Disassembly + remanufacturing & 4 \\
& Dissasembly scheduling & 3 \\
\hline
\end{tabular}

The quality of the returned products to be remanufactured is an important aspect to consider when organizing and planning remanufacturing activities. A common way of considering the quality of returned products is by assigning different degrees of quality and, depending on which, the necessary remanufacturing operations to which they must be submitted to meet customers demand may vary. In this sense, Jayaraman (2006), Ferguson et al. (2009) and Denizel et al. (2010) consider different quality levels for the products returned to remanufacturing facilities. Quality levels are another consideration in traditional production systems without remanufacturing, where customer requirements can be fulfilled by using products of a higher quality than demanded, as in TFT-LCD (Wu et al., 2010) or in float glass (Taskin and Uenal, 2009) industries. Defersha and Chen (2008) study the impact of run length on product quality, while Leung and Chan (2009) contemplate defective products production rates and the necessary machine repairing costs to increase the quality of manufactured products. Defective products from suppliers can affect production system yields and the quality of manufactured end products. Accordingly, Liang (2008) and Torabi and Hassini (2009) examine the defective rates of the products received from suppliers for the purpose of minimizing the total number of products rejected. Moreover, there are times when it is not possible to know the quality levels of the products received from suppliers in advance, and this aspect has to be modeled as an uncertain parameter (Zanjani et al., 2011, 2010a, 2010b). Table 13 presents the number of references addressing each quality extension.

Table 13. Extensions on quality

\begin{tabular}{lc}
\hline Quality extension & References \\
\hline Quality levels & 5 \\
Uncertain quality of products from suppliers & 3 \\
Defective product rates from suppliers & 2
\end{tabular}




\subsection{Modeling approach}

Since the 1950s, mathematical programming formulations have been proposed for a wide range of production-related problems to address problems of aggregate production planning, lot sizing and detailed short-term production scheduling, among others (Missbauer and Uzsoy, 2011). These formulations are optimization methods based on operations research, which determines the best possible production plan by generally minimizing total costs or by maximizing total profit. The typical mathematical programming approaches considered in production planning problems are linear programming, integer linear programming and mixed integer linear programming (MILP), and quadratic programming if there is a quadratic objective function of several variables subject to linear constraints in these variables. However, the need to optimize more than one objective simultaneously and to express the nonlinear relationships among the different variables of a production system involves the use of multi-objective programming (MOP) and nonlinear programming (NLP), respectively. Moreover, multi-stage decision processes can be modeled by dynamic programming (DP) approaches. Additionally, when the mathematical modeling of production systems dynamics proves a complex task, simulation models can prove a good alternative. Simulation can help firms become more aware of the dynamics and efficiency of their processes in a production planning context (Biswas and Narahari, 2004). However, simulation does not guarantee optimal solutions, so hybrid models which contemplate the use of simulation tools to complement mathematical programming models have appeared. According to Mula et al. (2006), there are many research works and applications which aim to formalize uncertainty in manufacturing systems. Stochastic programming (SP), fuzzy programming (FP), robust optimization (RO) and stochastic dynamic programming (SDP) are some of the most used approaches to model uncertainty in production planning problems (Sahinidis, 2004). Readers are referred to Aloulou et al. (2013), Dolgui and Prodhon (2007), Dolgui et al. (2013), Grosfeld-Nir and Gerchak (2004), Koh et al. (2002), Mula et al. (2006), Yang et al. (2007) and Ko et al. (2010) and Peidro et al. (2009) for reviews of modeling uncertainty in production planning and supply chain planning problems, respectively.

Table 14 shows the number of references relating to each modeling approach. The vast majority of the reviewed papers (165 references) opt for linear, mixed integer or integer linear programming-based modeling approaches, while only 3 references consider quadratic programs (Gonzalez-Ramirez et al., 2011; Haugen et al., 2007; Ibarra-Rojas et al., 2011). Moreover, Onal and Romeijn (2010) propose an integer and quadratic programming model to address different production planning problems with setup times and pricing decisions. Modeling two or more conflicting objectives is addressed by only 11 references, and only 2 references (Omar and Bennell, 2009; Omar and Teo, 2007) present both MILP and MOP models separately. In general terms, in order to solve multi-objective problems using a standard MILP solver, multi-objective programs are converted into an equivalent MILP model with goal programming or fuzzy programming approaches and their variants. In this sense, Li et al. (2006), Kanyalkar and Adil (2007), Leung and Ng (2007), Leung and Chan (2009), Omar and Teo (2007) and Omar and Bennell (2009) present goal programming (GP) approaches to solve their multi-objective problems, while Zolghadri et al. (2008) use a lexicographic linear goal programming method. Liang (2007, 2008) consider an FP approach, while Jamalnia and Soukhakian (2009), Petrovic and Akoez (2008) and Torabi and Hassini (2009) propose different fuzzy goal programming approaches. 
Although the inclusion of nonlinearities in models may be more realistic than linear relationships, the difficulty of solving NLP problems given their complexity and timeconsuming properties mean that they do not appear as frequently as linear models. Of the 11 references addressing nonlinearities, 5 (Ahkioon et al., 2009; Asmundsson et al., 2009; Defersha and Chen, 2008; Lin et al., 2009; Safaei and Tavakkoli-Moghaddam, 2009) propose linearization methods to accomplish solutions more easily, while Li and Meissner (2011) and Shi et al. (2011) respectively consider a discretization method and a Lagrangian relaxation procedure. Other solution approaches for nonlinear programs considered in the reviewed papers are genetic (Palaniappan and Jawahar, 2011) and column generation and gradient search algorithms (Sun et al., 2010). However, Qu and Williams (2008) use a commercial NLP solver with default settings to solve their proposed nonlinear model, whereas Fandel and StammenHegene (2006) present neither a solution procedure nor results. Lastly, Tian et al. (2011) propose an iterative method to solve a tactical production planning problem based on one linear and one nonlinear programming models.

One way of simplifying the solution process of a complex production planning problem is to divide it into several simpler subproblems in a recursive manner by using dynamic programming, as these authors do: Berk et al. (2008); Cheaitou et al. (2009); Hsu et al. (2009); Huh et al. (2010); Feng et al. (2011); Fleischhacker and Zhao (2011); Wu et al. (2011). Moreover, the simulation tools are used either in isolation (Alwan et al., 2008; Li et al., 2009b; Mohebbi et al., 2007) or combined with mathematical programming in hybrid models (Albey and Bilge, 2011; Almeder et al., 2009), which are complementary approaches that can be applied to model complex production planning problems. Other modeling approaches, such as Laplace transform (Bogataj and Bogataj, 2007; Grubbstrom and Huynh, 2006a, 2006b), heuristics (Ho et al., 2007, 2006) and MRP logic (Barba-Gutierrez et al., 2008; Ram et al., 2006), are also considered in the reviewed papers.

Uncertainty in the production environment is addressed by 39 references which employ different modeling approaches. Stochastic programming models are considered with distinct approaches, such as two-stage stochastic programming (Leung et al., 2006; Leung and Ng, 2007a; Nagar and Jain, 2008; Schütz and Tomasgard, 2011; Wu, 2011; Zanjani et al., 2011) or multi-stage stochastic programming (Brandimarte, 2006; Denizel et al., 2010; Guan and Miller, 2008; Guan et al., 2009; Guan and Philpott, 2011; Koerpeoglu et al., 2011; Nagar and Jain, 2008; Zanjani et al., 2010b). Other stochastic programming proposals are presented by Karabuk (2008), Kim and Xirouchakis (2010), Sodhi and Tang (2009), Tempelmeier and Herpers (2011) and Tempelmeier (2007). Most of these papers consider only demand uncertainty, but others also add uncertain costs (Leung and $\mathrm{Ng}, 2007 \mathrm{a}$ ), import quotas (Wu, 2011), quality of raw materials (Zanjani et al., 2010b) or other problem parameters (Guan and Miller, 2008; Tempelmeier, 2007). Moreover, Zanjani et al. (2011) also contemplate uncertain quality of raw materials, as do Denizel et al. (2010) and Guan and Philpott (2011), who examine uncertainty in the quality of returned products in a remanufacturing production system and for supplies in a dairy supply chain, respectively. Seven references introduce uncertain parameters into production planning problems by fuzzy programming (Chen and Huang, 2010; Demirli and Yimer, 2008; Lan et al., 2011; Mula et al., 2010b, 2008; Peidro et al., 2010; Zhang et al., 2011). Moreover, 3 other references (Liang, 2007; Petrovic and Akoez, 2008; Torabi and Hassini, 2009), which propose multi-objective models solved by developing an equivalent singleobjective model with fuzzy approaches, also address production problems in an uncertain environment. Among them, Demirli and Yimer (2008) contemplate uncertain operational costs, while Mula et al. (2010b) opt for uncertainty in market demand. The remaining references present different combinations of uncertain parameters added to uncertain demand, such as production costs (Lan et al., 2011), available capacities (Chen and Huang, 2010; Torabi and Hassini, 2009), capacities data and costs (Liang, 2007; Mula et al., 2008) raw material prices (Zhang et al., 2011), supply and process parameters (Peidro et al., 2010) or average sales and target inventory levels (Petrovic and Akoez, 2008). 
Of the remaining reviewed papers dealing with production planning problems with uncertainty, a group of 7 references (Aghezzaf et al., 2010; Leung et al., 2007a, 2007b; Mirzapour Al-ehashem et al., 2011; Wei et al., 2011; Wu et al., 2010; Zanjani et al., 2010a) proposes robust optimization approaches. Among them, Zanjani et al. (2010a) consider random yields due to uncertain quality levels of raw materials, while Aghezzaf et al. (2010) contemplate uncertainty in demand levels. Besides, Leung et al. (2007a, 2007b) present production planning models with uncertain demand and costs, Wu et al. (2010) do so, but with uncertain demand and sales prices, and Mirzapour Al-e-hashem et al. (2011) simultaneously do so with uncertain demand, costs and sales prices. Lastly, Wei et al. (2011) tackles a production planning problem with remanufacturing to face uncertain demand and returns quantities. In this sense, Ferguson et al. (2009), Li et al. (2009) and Naeem et al. (2013) study a production planning problem in a remanufacturing environment with the same uncertain parameters by proposing stochastic dynamic programming models. Azaron et al. (2009) and Cristobal et al. (2009) also opt for this modeling approach and they respectively model uncertain production costs and uncertain demands and production costs and available capacities

Table 14. Modeling approaches

\begin{tabular}{lc}
\hline Modeling approach & References \\
\hline Linear/Integer/Mixed integer linear programming & 165 \\
Stochastic programming & 18 \\
Nonlinear programming & 11 \\
Multi-objective programming & 11 \\
Fuzzy programming & 7 \\
Robust Optimization & 7 \\
Dynamic programming & 7 \\
Other analytical approaches & 4 \\
Stochastic Dynamic Programming & 5 \\
Simulation & 3 \\
Quadratic programming & 3 \\
Laplace transform & 3 \\
Hybrid models & 2 \\
Mixed integer/integer linear programming + Multi-objective programming & 2 \\
Linear/Integer/Mixed integer Linear programming + Quadratic programming & 1 \\
Linear/Integer/Mixed integer Linear programming + Nonlinear programming & 1 \\
\hline
\end{tabular}

\subsection{Solution approach}

According to Buschkühl et al. (2010), the approaches to solve different types of production planning or capacitated lot-sizing models can be classified into five groups: mathematical programming-based (MP-based) approaches, Lagrangian heuristics; decomposition and aggregation heuristics; metaheuristics; problem-specific and greedy heuristics.

Among the MP-based approaches, it is possible to distinguish between exact methods, which stop after an optimal solution has been found regardless of efforts made in terms of required computation time and memory, and MP-based heuristics, which only explores parts of the solution space and attempts to find a good feasible solution in a reasonable time. This work considers exact methods as those embedded in default solvers, such as the typical branch-andbound algorithm for solving mixed-integer programs to optimality. Fix-and-relax heuristics divide the problem to be solved into several subproblems with a view to reducing the number of binary variables to be treated simultaneously, which are distinguished as three different sets. The first is solved to optimality, the second is relaxed and the setup states that the third set is fixed to the values of a previous iteration (Buschkühl et al., 2010). In addition, column generation can be considered an efficient algorithm for solving larger linear programs. Based on 
the idea that most variables are nonbasic and assume a value of zero in the optimal solution, in theory it is necessary to consider only one subset of variables when solving the problem. In this sense, this solution method takes into account only those variables which have the potential to improve the objective function. Column generation can be hybridized with the branch-andbound algorithm to generate a solution method called branch-and-price. Rounding heuristics solution approaches are based on solving the mathematical programming problem by rounding up and rounding down fractional binary variables in relation to only a given threshold. Finally, primal-dual heuristics are based on the equivalence properties between primal and dual problems.

Other solution approaches to solve a difficult optimization problem by approximating it by a simpler one are Lagrangian heuristics, and decomposition and aggregation heuristics. Lagrangian heuristics includes iterative solution approaches based on Lagrangian relaxation. This method incurs an additional cost for the violations of relaxed inequality constraints by using Lagrangian multipliers. The solution to the relaxed problem comes very close to the optimal solution of the original problem. A special form of Lagrangian relaxation is the Lagrangian decomposition method, in which all the original constraints remain unaltered. The original problem is decomposed into subproblems by duplicating variables, where each subproblem only contains some constraints. For the solutions to the subproblems to become a valid solution to the original problem, duplicates must equal the corresponding original variables. These coupling constraints are finally relaxed (Buschkühl et al., 2010). On the other hand, aggregation heuristics is based on obtaining a reduced problem by omitting certain details and the subsequent division of the obtained solution. On the contrary, decomposition heuristics divides the original problem into subproblems and then coordinates the solutions obtained. Product-based, time-based and resource-based are the most popular decomposition and aggregation approaches to solve production planning problems.

Moreover, the impossibility of discovering the exact solutions corresponding to optimization problems and the need to respond to the practical situations considered in many real-world cases have led to an increased use of heuristic-type algorithms, which have proven to be valuable tools that provide solutions where exact algorithms do not (Verdegay et al., 2008). Metaheuristics have emerged as a result of the extensive application of these heuristic-type algorithms to many optimization problems. According to Voss et al. (1999), a metaheuristic can be defined as an iterative master process that guides and modifies the operations of subordinate heuristics to efficiently produce high quality solutions. Metaheuristic procedures start from an initially provided solution. By exploring the search space and by exploiting accumulated search experience, they are able to obtain non optimal solutions, which can largely satisfy the decision maker. Examples of metaheuristics algorithms include genetic algorithms (Holland, 1975), memetic algorithms (Moscato, 1989), variable neighborhood searches (Mladenović and Hansen, 1997), simulated annealing (Černý, 1985; Kirkpatrick et al., 1983), tabu searches (Glover and McMillan, 1986; Glover, 1989, 1990), ant colony optimization (Dorigo et al., 1996), bee colony optimization (Pham et al., 2005), particle swarm optimization (Kennedy and Eberhart, 1995; Shi and Eberhart, 1998), greedy randomized adaptive search procedure (GRASP) (Feo and Resende, 1989), scatter searches and path relinking (Glover, 1998; Glover et al., 2000), etc. This classification also contemplates other specific solution methods based on the problem structure and its properties: constructive heuristic algorithms; greedy algorithms; dynamic programmingbased algorithms.

Table 15 presents the solution approaches proposed in the reviewed papers. Most analyzed works opt for MP-based approaches, especially exact methods, which are embedded by default in typical solvers (82 references). Moreover, these exact methods are also presented in combination with other solution approaches, such as Lagrangian relaxation (Brahimi et al., 2010), ant colony optimization (Almeder, 2010; Pitakaso et al., 2007), GRASP (Mateus et al., 2010) and dynamic programming algorithms (Akbalik and Penz, 2011). Furthermore, several solution methods based on fix-and-relax heuristics are proposed by Brandimarte (2006), 
Akartunali and Miller (2009), Ferreira et al. (2009, 2010) and Toso et al. (2009). Column generation solution procedures are presented as being hybridized in branch-and-price algorithms (Degraeve and Jans, 2007; Onal and Romeijn, 2010), and are combined with gradient search procedures (Sun et al., 2010). Primal-dual heuristics and rounding heuristics are used only by Eksioglu et al. (2006) and Denizel and Sural (2006), respectively. Another class of MP-based heuristics called fix-and-optimize heuristics is proposed by Sahling et al. (2009) and Helber and Sahling (2010). Finally, other combinations of MP-based heuristics can be found in Stadtler and Sahling (2013) which propose a solution approach based on fix-and-relax and fix-and-optimize procedures; Lang and Shen (2011), which combine relax-and-fix, fix-and-optimize and timedecomposition approaches; De Araujo et al. (2008) and James and Almada-Lobo (2011), who present relax-and-fix heuristics and different metaheuristic solution procedures simultaneously; Goren et al (2012) who propose a hybrid solution method base don fix-and-optimize and genetic algorithms; Aghezzaf (2007), who combines primal-dual heuristics with a Lagrangian relaxation approach; Merzifonluoglu and Geunes (2006), who propose a dual-based heuristic algorithm and a dynamic programming-based one.

Fourteen references propose Lagrangian heuristics as a solution approach. Of these, 13 opt for Lagrangian relaxation with different combinations and 2 for Lagrangian decomposition methods. Regarding the papers that propose Lagrangian relaxation approaches, a group of 6 references (Brahimi et al., 2006a; Haugen et al., 2007; Kim and Xirouchakis, 2010; Shi et al., 2011; Tonaki and Toledo, 2010; Zhang et al., 2012) presents this solution method in isolation, while 4 references (Gramani et al., 2009; Rizk et al., 2006b; Sural et al., 2009; Toledo and Armentano, 2006) propose its combination with a subgradient optimization paradigm. Another combination of Lagrangian relaxation heuristics with a dynamic programming algorithm can be found in Tempelmeier and Buschkuehl (2009). Lagrangian relaxation is considered by Eksioglu et al. (2007) and Gunnarsson and Ronnqvist (2008), who complement this solution approach with a subgradient algorithm. Decomposition heuristics is used as a solution approach in 3 references, where Denton et al. (2006) exploit the supply chain structure of the MILP model by employing an product-based decomposition heuristics as a presolving stage to obtain a nearoptimal solution before obtaining a final one. Ouhimmou et al. (2008) use a time-decomposition approach to obtain good solutions in a reasonable time limit for large-sized problems. Other decomposition heuristics combinations with MP-based heuristics can be found in Lang and Shen (2011).

Thirty references include different metaheuristics to efficiently solve production planning problems. Among them, genetic algorithms are the most used metaheuristics, which are proposed by 11 references (Bjork and Carlsson, 2007; Defersha and Chen, 2008; Jamalnia and Soukhakian, 2009; Jozefowska and Zimniak, 2008; Li et al., 2009b, 2007; Liu et al., 2008; Palaniappan and Jawahar, 2011; Santos et al., 2010; Toledo et al., 2009; Yimer and Demirli, 2010). GRASP metaheuristics is considered in 4 references and is combined with other solution approaches, such as exact methods (Mateus et al., 2010), memetic algorithms (Boudia and Prins, 2009), path relinking (Nascimento et al., 2010) and path relinking and a reactive mechanism (Boudia et al., 2007). Tabu search algorithms are also associated with path relinking procedures (Armentano et al., 2011) and have been developed simultaneously with variable neighborhood metaheuristics (Almada-Lobo and James, 2010). Other applications of tabu search approaches can be found in Bard and Nananukul (2009), Karimi et al. (2006), Lukac et al. (2008) and Pineyro and Viera (2010). Besides other search solution procedures, such as neighborhood search strategies or variable neighborhood search-based metaheuristic, are applied by Aksen (2007), Almada-Lobo et al. (2008), James and Almada-Lobo (2011) and Xiao et al. (2011a, 2011b). Several references consider solution procedures based on metaheuristics inspired in nature phenomena or animal behavior, such as ant colony optimization (Almeder, 2010; Pitakaso et al., 2007, 2006), monkey algorithms (Lan et al., 2011), particle swarm optimization and bee colony optimization (Pal et al., 2011), simulated annealing (De Araujo et al., 2008) or scatter evolutionary algorithms (Zhang et al., 2011). 
Finally, specific solution methods, such as constructive heuristics or tailored algorithms, hierarchical solution methods or simulation frameworks, are proposed in 56 references, while greedy heuristics is considered in 4 of the reviewed works (Bollapragada et al., 2011; Boudia et al., 2008; Ferguson et al., 2009; Mocquillon et al., 2011). Other solution methods, such as dynamic programming-based algorithms, are presented in 34 of the analyzed papers.

Table 15. Solution approaches

\begin{tabular}{|c|c|c|}
\hline Solution approaches & & References \\
\hline \multirow{8}{*}{ Mathematical programming-based } & Exact methods & 82 \\
\hline & Fix-and-relax heuristics & 5 \\
\hline & Column generation and/or branch and price & 3 \\
\hline & Fix-and-optimize heuristics & 2 \\
\hline & Primal-dual heuristics & 1 \\
\hline & Rounding heuristics & 1 \\
\hline & Other combinations of exact methods & 5 \\
\hline & Other mathematical programming-based & 7 \\
\hline \multirow{5}{*}{ Lagrangian heuristics } & Lagrangian relaxation & 6 \\
\hline & Lagrangian relaxation and subgradient algorithm & 4 \\
\hline & Lagrangian decomposition & 1 \\
\hline & Lagrangian decomposition and subgradient algorithm & 1 \\
\hline & Other Lagrangian relaxation combinations & 3 \\
\hline \multirow{3}{*}{$\begin{array}{c}\text { Decomposition and aggregation } \\
\text { heuristics }\end{array}$} & Product-based decomposition heuristics & 1 \\
\hline & Time-decomposition heuristics & 1 \\
\hline & Other decomposition heuristics combinations & 1 \\
\hline \multirow{6}{*}{ Metaheuristics } & Genetic algorithm & 11 \\
\hline & Tabu search combinations & 6 \\
\hline & Neighborhood search and Variable neighborhood search & 5 \\
\hline & GRASP combinations & 4 \\
\hline & Ant Colony & 3 \\
\hline & Other metaheuristics & 4 \\
\hline \multirow{3}{*}{$\begin{array}{l}\text { Problem-specific, greedy heuristics } \\
\text { and dynamic programming approaches }\end{array}$} & Specific solution method & 56 \\
\hline & Greedy algorithms & 4 \\
\hline & Dynamic programming algorithms & 34 \\
\hline
\end{tabular}

\subsection{Development tool}

Sixty-three references do not provide any implementation or development details. However, 180 references report the names of the tools used to develop and solve the proposed production planning models. These software tools can be solvers (CPLEX, LINGO, Xpress-MP, Gurobi, LP-Solve, GLPK, etc.), programming languages (C, C++, Visual C, Java, Basic, Fortran, etc.), optimization modeling languages (GAMS, AMPL, OPL, AIMMS, MPL, Matlab, XpressMOSEL, etc.) and simulation systems (Anylogic, Arena, FMS.net, AutoSchedAP, etc.).

Tables 16a, 16b, 16c and 16d show the various main combinations associated with each development tool, classified as solvers, programming languages, modeling languages, simulation systems and other software tools. CPLEX solver is the most widely used tool and is reported in 102 references. In 27 of them, CPLEX appears as the only development tool, while it is used jointly with the $\mathrm{C}$ programming language in 24 articles. Besides, CPLEX is combined with other programming languages such as Java (Akbalik and Penz, 2011, 2009; Bard and Nananukul, 2009; Lang and Domschke, 2010; Lang and Shen, 2011) or Delphi (Helber and Sahling, 2010; Rizk et al., 2006b; Sahling et al., 2009). Moreover, CPLEX is frequently associated with optimization modeling tools such as OPL (Aghezzaf et al., 2011, 2010; Bilgen 
and Guenther, 2010; Feng et al., 2010, 2008; Kaczmarczyk, 2011; Quadt and Kuhn, 2009; Zanjani et al., 2010a, 2010b; Zhang et al., 2012), AMPL (Clark et al., 2010; Drechsel and Kimms, 2011; Ferreira et al., 2010, 2009; Gunnarsson and Ronnqvist, 2008; Tempelmeier and Buschkuehl, 2008; Toso et al., 2009), GAMS (Al-Ameri et al., 2008; Ibarra-Rojas et al., 2011; Pineyro and Viera, 2010; Stadtler and Sahling, 2013; Wu et al., 2011b) or MPL (Mula et al., 2010b, 2008; Peidro et al., 2010). Nine references report XPress-MP solver as the development tool (Anily et al., 2009; Asmundsson et al., 2009; Najid et al., 2011; Pochet and Wolsey, 2010; Schütz and Tomasgard, 2011; Stadtler, 2011; Suerie, 2006; Van Vyve and Wolsey, 2006; Van Vyve, 2006) and it is combined with the C programming language in Brahimi et al. (2006a, 2010). Other commercial solvers, like Gurobi, Minos and OSL, can be found in Lu and Qi (2011), Qu and Williams (2008) and Torabi and Hassini (2009), respectively. Besides, other non commercial solvers are considered an optimization tool by Bjork and Carlsson (2007) and Gonzalez-Ramirez et al. (2011), who use LP-Solve, Christou and Ponis (2009), and who opt for QSOpt running in the NEOS Server (Czyzyk et al., 1998; Gropp and Moré, 1997), and by Haugen et al. (2007) who develop an optimization algorithm with Java and LOQO solver.

The second most frequently used tool considered in the reviewed papers is the $\mathrm{C}$ programming language and its variants, such as $\mathrm{C}++$ or Visual $\mathrm{C}$, which appears in 49 references. Apart from its combination with CPLEX solver, the C programming language is used in isolation (in 13 references), or is combined with other modeling systems such as Lingo (Karimi et al., 2006; Palaniappan and Jawahar, 2011; Petrovic and Akoez, 2008; Yimer and Demirli, 2010), or with optimization solvers such as Xpress-MP (Brahimi et al., 2010, 2006a). Moreover, other combinations with GAMS, AMPL, OPL, CPLEX and LP-Solve, among others, have been found in this review work. Among the other programming languages, Java is the second most used with 11 references, Delphi appears in 6 articles, while Fortran and Basic are reported in 3 articles each. Apart from their combinations with CPLEX, these programming languages are used in isolation to develop solution algorithms; e.g., Feng et al. (2011) and Okhrin and Richter (2011a, 2011b), who use Java, Boudia and Prins (2009) and Boudia et al. (2008, 2007), who opt for Delphi, and Ho et al. $(2007,2006)$ who use Fortran. On the other hand, Basic is used jointly with other software tools such as MS Excel (Baptiste et al., 2008; Depuy et al., 2007) or Lingo (Wu et al., 2010).

Lingo is the modeling language most frequently used in the reviewed papers as it appears in 26 references, of which 16 employ it as the only development tool. In the rest of the articles, it is utilized in combination with the C programming language, Matlab ( $\mathrm{Li}$ et al., 2007, 2006b) or other software tools. The second most frequently used modeling system is OPL, considered in 15 references. Apart from its combination with CPLEX, OPL is used in isolation in 2 references (Jung et al., 2008a; Kefeli et al., 2011) or is combined with other development tools, such as Java, CPLEX or Minitab. Besides, AMPL and GAMS are used mainly with CPLEX solver, and are presented in 11 and 9 references, respectively, while Xpress-MOSEL is presented as the main development tool in Akartunali and Miller (2009), Akbalik and Pochet (2009) and Transchel et al. (2011). Although Matlab is not an optimization modeling language, it is employed for its good performance and given its possibility of being linked with standard solvers or programming tools. Of all the reviewed papers, Matlab is used in isolation in 3 references (Azaron et al., 2009; Naeem et al., 2013; Shi et al., 2011), and is linked with Lingo in 2 references, and with other combinations in 3 references (Brandimarte, 2006; Li et al., 2011; Pal et al., 2011). Finally, WINQSB is used as development tool in Erromdhani et al. (2012). On the other hand, the reviewed papers contemplate several simulation systems in isolation, such as Arena ( $\mathrm{Li}$ et al., 2009b) or AutoSchedAP (Chen et al., 2010), or in combination with solvers, such as Anylogic (Almeder et al., 2009) and FMS.net (Albey and Bilge, 2011).

Despite the large number of tools detailed in the reviewed papers, it is worth highlighting that their integration with commercial information systems is reported only by Mehrotra et al. (2011) who combine CPLEX with SAP ERP, and by Jozefowska and Zimniak (2008) who develop a decision support system which interacts with Microsoft Dynamics Axapta. 
Table 16a. Solvers used and main combinations

\begin{tabular}{clc}
\hline Solvers & Main combinations & References \\
& & 27 \\
& CPLEX & 24 \\
& C+CPLEX & 10 \\
CPLEX & OPL+CPLEX & 7 \\
(102 references) & AMPL+CPLEX & 5 \\
& Java+CPLEX & 5 \\
& GAMS+CPLEX & 3 \\
& DELPHI+CPLEX & 3 \\
\hline Xpress-MP & MPL+CPLEX & 9 \\
(13 references) & Xpress-MP & 2 \\
\hline LP-Solve & C+Xpress-MP & 1 \\
(2 references) & LP-Solve & 1 \\
\hline Other solvers & AMPL+CPLEX+C+LP-Solve & 6 \\
\hline
\end{tabular}

Table 16b. Programming languages used and main combinations

\begin{tabular}{clc}
\hline Programming languages & Main combinations & References \\
\hline & C+CPLEX & 24 \\
C/C++/Visual C & C & 13 \\
(49 references) & C+LINGO & 4 \\
& C+Xpress-MP & 2 \\
\hline Java & Java+CPLEX & 5 \\
(11 references) & Java & 3 \\
\hline Delphi & DELPHI & 3 \\
(6 references) & DELPHI+CPLEX & 3 \\
\hline Fortran & Fortran & 2 \\
(3 references) & Fortran+LINGO & 1 \\
\hline Basic & Basic+Excel & 2 \\
(3 references) & Basic+LINGO & 1 \\
\hline
\end{tabular}

Table 16c. Modeling languages used and main combinations

\begin{tabular}{clc}
\hline Modeling languages & Main combinations & References \\
\hline \multicolumn{1}{c}{ Lindo/Lingo } & LINGO & 16 \\
(26 references) & C+LINGO & 4 \\
& MATLAB+LINGO & 2 \\
\hline \multicolumn{1}{c}{ OPL } & OPL+CPLEX & 10 \\
(15 references) & OPL & 2 \\
\hline \multicolumn{1}{c}{ AMPL } & AMPL+CPLEX & 7 \\
\hline \multicolumn{1}{c}{ GAMS } & GAMS+CPLEX & 5 \\
\hline \multicolumn{1}{c}{ (8 references) } & MATLAB & 3 \\
MPL & MATLAB+LINGO & 2 \\
Xpress-Mosel & MPL+CPLEX & 3 \\
AIMMS & Xpress-Mosel & 3 \\
WINQSB & AIMMS+CPLEX & 1 \\
\hline
\end{tabular}

Table 16d. Simulation systems used and main combinations

\begin{tabular}{llc}
\hline Simulation systems & Main combinations & References \\
\hline AnyLogic & AnyLogic+Xpress-MP & 1 \\
Arena & Arena & 1 \\
AutoSchedAP & AutoSchedAP & 1 \\
FMS.net & FMS.net+CPLEX & 1 \\
\hline
\end{tabular}




\subsection{Application}

The proposed models can be validated by using data from real-world production systems or by carrying out numerical experiments based on artificially generated instances. Of the 250 papers analyzed, 71 were validated by practical applications in real-world environments and 160 by numerical experiments, 18 of which were inspired in real practices from several industrial sectors. Moreover, 14 references do not present any application result. Tables 17 and 18 present the industrial areas in which each reference was validated with a practical application or with a numerical experiment inspired in real environments, respectively. These tables show the variety of industries in which the reviewed models were validated; sawmills, wood and furniture, automobile and semiconductor and electronic devices industries in the case of practical applications, and processed food, beverages and dairy and pulp and paper industries with regard to numerical experiments, are highlighted.

Table 17. Practical applications

\begin{tabular}{|c|c|c|}
\hline Practical applications & $\begin{array}{l}\text { Number of } \\
\text { references }\end{array}$ & References \\
\hline $\begin{array}{l}\text { Sawmills, wood and furniture } \\
\text { industry }\end{array}$ & 9 & $\begin{array}{l}\text { Feng et al. (2008); Liu et al. (2008); Liu and Tu (2008b); } \\
\text { Ouhimmou et al. (2008); Pastor et al. (2009); Feng et al. (2010); } \\
\text { Zanjani et al. (2010a); Zanjani et al. (2010b); Zanjani et al. } \\
\text { (2011) }\end{array}$ \\
\hline Automobile industry & 7 & $\begin{array}{l}\text { Mula et al. (2008); Qu and Williams (2008); Tempelmeier and } \\
\text { Buschkuehl (2008); Zolghadri et al. (2008); Torabi and Hassini } \\
\text { (2009); Peidro et al. (2010); Zhang et al. (2011) }\end{array}$ \\
\hline $\begin{array}{l}\text { Semiconductor and electronic } \\
\text { devices industry }\end{array}$ & 7 & $\begin{array}{l}\text { Denton et al. (2006); Jayaraman (2006); Depuy et al. (2007); Lin } \\
\text { et al. (2009); Chen et al. (2010); Wu et al. (2010); Tian et al. } \\
\text { (2011) }\end{array}$ \\
\hline Textile industry & 5 & $\begin{array}{l}\text { Leung et al. (2006); Bjork and Carlsson (2007); Leung et al. } \\
\text { (2007b); Karabuk (2008); Wu (2011) }\end{array}$ \\
\hline $\begin{array}{l}\text { Foundry, steel and machinery } \\
\text { industry }\end{array}$ & 4 & $\begin{array}{l}\text { Liang (2007); De Araujo et al. (2008); Genin et al. (2008); } \\
\text { Tonaki and Toledo (2010) }\end{array}$ \\
\hline $\begin{array}{l}\text { Fruit juice and soft drink } \\
\text { industry }\end{array}$ & 4 & $\begin{array}{l}\text { Liang (2008); Toledo et al. (2009); Bilgen and Guenther (2010); } \\
\text { Ferreira et al. (2010) }\end{array}$ \\
\hline $\begin{array}{l}\text { Processed food, beverages and } \\
\text { dairy industry }\end{array}$ & 5 & $\begin{array}{l}\text { Christou and Ponis (2009); Guan and Philpott (2011); Mehrotra } \\
\text { et al. (2011); Schütz and Tomasgard (2011); Erromdhani et al. } \\
\text { (2012) }\end{array}$ \\
\hline Pulp and paper industry & 4 & $\begin{array}{l}\text { Bouchriha et al. (2007); Gunnarsson and Ronnqvist (2008); Rizk } \\
\text { et al. (2008); Mirzapour Al-e-hashem et al. (2011) }\end{array}$ \\
\hline Toy industry & 3 & $\begin{array}{l}\text { Leung and Ng (2007a); Leung and Ng (2007b); Leung et al. } \\
\text { (2007a); }\end{array}$ \\
\hline Animal nutrition industry & 2 & Toso et al. (2009); Clark et al. (2010) \\
\hline Consumer goods manufacturers & 2 & Van Vyve and Wolsey (2006); Kanyalkar and Adil (2007) \\
\hline Glass manufacturers & 2 & Almada-Lobo et al. (2008); Taskin and Uenal (2009) \\
\hline Hygiene products industry & 2 & Mocquillon et al. (2011); Shaikh et al. (2011) \\
\hline $\begin{array}{l}\text { Mail management systems } \\
\text { manufacturers }\end{array}$ & 2 & Ferguson et al. (2009); Denizel et al. (2010) \\
\hline Refinery industry & 2 & Liu et al. (2007); Liu and Tu (2008) \\
\hline
\end{tabular}




\begin{tabular}{|c|c|c|}
\hline Practical applications & $\begin{array}{l}\text { Number of } \\
\text { references }\end{array}$ & References \\
\hline Pharmaceutical company & 1 & Stadtler (2011) \\
\hline $\begin{array}{l}\text { Photographic film-producing } \\
\text { company }\end{array}$ & 1 & Van den broecke et al. (2008) \\
\hline Plastic industry & 1 & Jozefowska and Zimniak (2008) \\
\hline Refrigerators manufacturer & 1 & Jamalnia and Soukhakian (2009) \\
\hline $\begin{array}{l}\text { Remanufacturer of computers } \\
\text { and laptops }\end{array}$ & 1 & Li et al. (2009b) \\
\hline Remanufacturer of tools & 1 & Li et al. (2009a) \\
\hline Resin manufacturer & 1 & Omar and Teo (2007) \\
\hline $\begin{array}{l}\text { Surface and material science } \\
\text { company }\end{array}$ & 1 & Leung and Chan (2009) \\
\hline Surfactant manufacturer & 1 & Transchel et al. (2011) \\
\hline Valve manufacturing company & 1 & Timm and Blecken (2011) \\
\hline Not provided & 1 & Baptiste et al. (2008) \\
\hline TOTAL & 70 & \\
\hline
\end{tabular}

Table 18. Numerical experiments inspired in real environments

\begin{tabular}{|c|c|c|}
\hline $\begin{array}{l}\text { Numerical examples inspired } \\
\text { in: }\end{array}$ & $\begin{array}{l}\text { Number of } \\
\text { references }\end{array}$ & References \\
\hline $\begin{array}{l}\text { Processed food, beverages and } \\
\text { dairy industry }\end{array}$ & 2 & Ram et al. (2006), Christou et al. (2007) \\
\hline Pulp and paper industry & 2 & Rizk et al. (2006), Almeder et al. (2009) \\
\hline $\begin{array}{l}\text { Sawmills, wood and furniture } \\
\text { industry }\end{array}$ & 1 & Demirli and Yimer (2008) \\
\hline Pharmaceutical company & 1 & Lukac et al. (2008) \\
\hline Pottery company & 1 & Petrovic and Akoez (2008) \\
\hline $\begin{array}{l}\text { Fruit juice and soft drink } \\
\text { industry }\end{array}$ & 1 & Ferreira et al. (2009) \\
\hline Iron factory & 1 & Pan et al. (2009) \\
\hline $\begin{array}{l}\text { Semiconductor and electronic } \\
\text { devices industry }\end{array}$ & 1 & Quadt and Kuhn (2009) \\
\hline Magazine publishing firm & 1 & Huh et al. (2010) \\
\hline Refractory bricks manufacturer & 1 & Mateus et al. (2010) \\
\hline X-ray film producer & 1 & Aghezzaf et al. (2011) \\
\hline Clinical trial & 1 & Fleischhacker and Zhao (2011) \\
\hline
\end{tabular}




\begin{tabular}{lcc}
\hline $\begin{array}{l}\text { Numerical examples inspired } \\
\text { in: }\end{array}$ & $\begin{array}{l}\text { Number of } \\
\text { references }\end{array}$ & References \\
\hline Automobile industry & 1 & Koerpeoglu et al. (2011) \\
Plastic industry & 1 & Lang and Shen (2011) \\
Poultry industry & 1 & Lu and Qi (2011) \\
$\begin{array}{l}\text { Remanufacturing of printers and } \\
\text { Copy cartridges }\end{array}$ & 1 & Wei et al. (2011) \\
\hline $\begin{array}{l}\text { TOTAL } \\
\text { TOT }\end{array}$ & 18 & \\
\hline
\end{tabular}

\subsection{Limitations}

Some of the limitations pointed out by the authors of the proposals are related to the solution method used, the considered production systems, demand issues, capacities, the non consideration of uncertain parameters, product properties, applications in non real-world environments, supply chain issues and costs. These limitations are possibly improvements of the proposed models and they identify future lines of work for academic researchers and practitioners.

Table 19 provides details of the different limitations associated with all the previous groups according to the authors. A hundred and two references present limitations related to solution methods. Among them, the vast majority (90 references) obtain improvable solutions in terms of the optimality or CPU time needed with the considered solution procedure. One group of 4 references (Fandel and Stammen-Hegene, 2006; Grubbstrom and Huynh, 2006a; Tempelmeier and Buschkuehl, 2009; Zolghadri et al., 2008) proposes models with a high grade of complexity due to the number of variables considered or to the mathematical expressions included, and are considered time-consuming solution procedures. The changes made in the information on production or market environments in Cheaitou et al. (2009), Wei et al. (2011) and Wu (2011) are not considered with a proper updating information method embedded in the solution process. Moreover, Galasso et al. (2009) and Leung et al. (2006) point out that the variations in specific parameters made by a sensitivity analysis are a weak point.

Production system limitations are indicated in 49 references. These weaknesses are due mainly to single-machine production environments and other parameters such as setups, lead times or safety stocks. Hence, a group of 14 references model production systems report only one production resource (Aghezzaf et al., 2007; Almada-Lobo and James, 2010; Almada-Lobo et al., 2007; Bouchriha et al., 2007; Gicquel et al., 2009; Koerpeoglu et al., 2011; Lang and Shen, 2011; Menezes et al., 2011; Ozturk and Ornek, 2010; Petrovic and Akoez, 2008; Sahling et al., 2009; Schulz, 2011; Stadtler, 2011; Stadtler and Sahling, 2013). Furthermore, setup limitations are caused by not considering setup times (Asmundsson et al., 2009; Brahimi et al., 2010; Deng and Yano, 2006; Gicquel et al., 2009; Grubbstrom and Huynh, 2006a), setup carry-overs (Helber and Sahling, 2010; Kaczmarczyk, 2011; Nascimento et al., 2010), setup sequencedependents (Goren et al., 2012; Mohan et al., 2012; Ozturk and Ornek, 2010) or setup groups (Absi and Kedad-Sidhoum, 2008). Moreover, Bjork and Carlsson (2007) and Merzifonluoglu et al. (2007) do not reflect lead time flexibility, while Aghezzaf et al. (2007), Kanyalkar and Adil (2007) and Rong et al. (2006) assume that lead times are zero. Alwan et al. (2008), Brandimarte (2006), Kanyalkar and Adil (2007) and Selcuk et al. (2006) do not include safety stocks as a model parameter in their proposals. Other production system limitations are related to the inclusion of disposal activities in remanufacturing systems (Defersha and Chen, 2008; Li et al., 2006b) and the small bucket modeling approach (Lang and Domschke, 2010; Sahling et al., 2009). 
Demand limitations are described in 37 references. These weaknesses are due to not allowing backorders (Aksen, 2007; Almada-Lobo et al., 2007; Begnaud et al., 2009; Bilgen and Guenther, 2010; Bollapragada et al., 2011; Degraeve and Jans, 2007; Gaglioppa et al., 2008; Goren et al., 2012; Gutierrez et al., 2008; Kanyalkar and Adil, 2007; Lan et al., 2011; Liu and Tu, 2008a; Lusa et al., 2009; Menezes et al., 2011; Wolsey, 2006), lost sales (Bollapragada et al., 2011; Liu and Tu, 2008b), or are owing to not including pricing decisions (Bjork and Carlsson, 2007; Feng et al., 2010; Geunes et al., 2006; Huh et al., 2010; Jayaraman, 2006; Leung et al., 2006; Lu and Qi, 2011; Onal and Romeijn, 2010; Sargut and Romeijn, 2007; Shi et al., 2011; Xue et al., 2011) or discounts (Aksen, 2007; Ho et al., 2007). The other demand limitations reported by authors consider constant selling prices (Feng et al., 2008; van den Heuvel and Wagelmans, 2006), assume monopolistic demand (Haugen et al., 2007), or ignore demand patterns and seasonal demand (Alwan et al., 2008; Zanjani et al., 2010b), segregation of customers (Leung and Ng, 2007a) or time windows (Absi et al., 2011).

The capacity limitations pointed out by the authors are due to not considering production capacities (Aksen, 2007; Depuy et al., 2007; Ho et al., 2006; Kim et al., 2006; Li et al., 2006b; Liu et al., 2007; Merzifonluoglu and Geunes, 2006; Okhrin and Richter, 2011a; Palaniappan and Jawahar, 2011; Pitakaso et al., 2007; Rizk et al., 2006a; Tempelmeier, 2007; van den Heuvel and Wagelmans, 2006; van den Heuvel et al., 2007), storage capacities (Almada-Lobo and James, 2010; Bollapragada et al., 2011; Gonzalez-Ramirez et al., 2011; Gunnarsson and Ronnqvist, 2008; Stadtler and Sahling, 2013), outsourcing capacities (Erromdhani et al., 2012; Fleischhacker and Zhao, 2011; Gonzalez-Ramirez et al., 2011; Liu and Tu, 2008b; Ozturk and Ornek, 2010), overtime production capacities (Bilgen and Guenther, 2010; Gonzalez-Ramirez et al., 2011; Palaniappan and Jawahar, 2011) or transport capacities (Hwang, 2010; Sargut and Romeijn, 2007).

Product-related limitations appear in those papers addressing the production of only a single product (18 references) or in those that consider only mono-level product structures (Alwan et al., 2008; Degraeve and Jans, 2007; Gaglioppa et al., 2008; Ho et al., 2007, 2006; Kim and Xirouchakis, 2010; Mohan et al., 2012; Nascimento et al., 2010). Moreover, the product structures of Barba-Gutierrez et al. (2008), Kim and Xirouchakis (2010) and Ram et al. (2006) do not bear in mind possible product commonalities. Supply chain limitations are related to the specific nodes not included in the supply chain structure, such as suppliers (Jung et al., 2008a; Yang and Qi, 2010), more production plants (Guan and Philpott, 2011), warehouses (Guan and Philpott, 2011; Shaikh et al., 2011), distribution centers (Erromdhani et al., 2012; Torabi and Hassini, 2009), vendors (Jung et al., 2008b) or supplying very simple chain networks (Dudek and Stadtler, 2007; Fleischhacker and Zhao, 2011; Huh et al., 2010; Rizk et al., 2006a; Selcuk et al., 2008). Moreover, transport issues and supplier selection are reported as drawbacks in Bilgen and Guenther (2010), Chen and Huang (2010), Gunnarsson and Ronnqvist (2008), Qu and Williams (2008), and Lin et al. (2009) and Pal et al. (2011). Finally, the main limitation in relation to costs is the omission of setup costs, as pointed out by Bouchriha et al. (2007), Gramani and Franca (2006), Li et al. (2007), Ornek and Cengiz (2006) and Romero and Vermeulen (2009). The rest of cost drawbacks are due to contemplating constant costs over time (Azaron et al., 2009; Smith and Martinez-Flores, 2007), and to not considering transport costs (Chand et al., 2007), holding costs (Hwang, 2007), plant-specific manufacturing costs (Kanyalkar and Adil, 2007) or salvage costs (Hsu et al., 2009).

Table 19. Main limitations of the reviewed works

\begin{tabular}{clc}
\hline Type & Limitation & References \\
\hline \multirow{3}{*}{ Solution method } & Solution quality/procedure & 90 \\
(102 references) & Model complexity & 4 \\
& Information update in solution process & 3 \\
& Sensitivity analysis on parameters & 2 \\
& Other solution method limitations & 3 \\
\hline \multirow{2}{*}{ Production system } & Single-machine & 14 \\
& Setup limitations & 12
\end{tabular}




\begin{tabular}{|c|c|c|}
\hline \multirow[t]{5}{*}{ (49 references) } & Lead time limitations & 5 \\
\hline & Safety stocks not considered & 4 \\
\hline & Disposal activities not considered & 2 \\
\hline & Small-bucket modeling approach & 2 \\
\hline & Other product system limitations & 7 \\
\hline \multirow{6}{*}{$\begin{array}{c}\text { Demand } \\
\text { (37 references) }\end{array}$} & Backorders not allowed & 15 \\
\hline & Pricing decisions not included & 11 \\
\hline & Constant price & 2 \\
\hline & Discounts not considered & 2 \\
\hline & Lost sales not considered & 2 \\
\hline & Other demand limitations & 5 \\
\hline \multirow{6}{*}{$\begin{array}{c}\text { Capacities } \\
\text { (35 references) }\end{array}$} & Production capacity not considered & 14 \\
\hline & Stationary production capacities & 6 \\
\hline & Storage capacity not considered & 5 \\
\hline & Outsourcing capacity not considered & 5 \\
\hline & Overtime capacity not considered & 3 \\
\hline & Transport capacity not considered & 2 \\
\hline $\begin{array}{c}\text { Uncertainty } \\
\text { (34 references) }\end{array}$ & Uncertainty not considered in parameters & 34 \\
\hline \multirow{4}{*}{$\begin{array}{c}\text { Product } \\
\text { (32 references) }\end{array}$} & Single-product & 18 \\
\hline & Multi-level product structures not considered & 8 \\
\hline & Products commonality not considered & 3 \\
\hline & Other product limitations & 3 \\
\hline $\begin{array}{c}\text { Application } \\
\text { (30 references) }\end{array}$ & Application in non real environments & 30 \\
\hline \multirow{3}{*}{$\begin{array}{l}\text { Supply chain } \\
\text { (18 references) }\end{array}$} & Supply chain structure & 12 \\
\hline & Transport issues not considered & 4 \\
\hline & Supplier selection process not included & 2 \\
\hline \multirow{2}{*}{$\begin{array}{c}\text { Costs } \\
\text { (13 references) }\end{array}$} & Setup costs not considered & 5 \\
\hline & Other costs limitations & 8 \\
\hline
\end{tabular}

\subsection{Benefits}

Table 20 summarizes the main benefits pointed out by the reviewed references reported by their authors. In this work, benefits are classified into six groups: solution method, improvements, application, uncertainty, extensions and demand. Two hundred references present benefits relating to the solution method used. The vast majority (187 references) obtain good solutions in terms of either the CPU time needed or optimality, or they present solution procedures that outperform previous methods in the literature. Moreover, 11 references (Aghezzaf et al., 2011; Brahimi et al., 2006a; Genin et al., 2008; Leung and Chan, 2009; Leung and Ng, 2007b; Ornek and Cengiz, 2006; Rizk et al., 2006b; Van den broecke et al., 2008; Wei et al., 2011; Wu et al., 2010; Zanjani et al., 2010a) stand out for their robustness from the rest; namely, they are not affected when the problem parameters are varied. In this sense, flexibility in lead times (Bjork and Carlsson, 2007), routing and processes (Ahkioon et al., 2009), transport capacity (Hwang et al., 2010), related to uncertainty or different scenarios (Erromdhani et al., 2012; Leung and Chan, 2009; Schütz and Tomasgard, 2011) and to modeling new constraints (Helber and Sahling, 2010) are an important advantage in dynamic production environments.

In all, there are 31 references which achieve significant improvements of different outputs of the proposed tactical production planning models. Most provide improvements in inventory levels or total inventory costs (Chen et al., 2010; Denton et al., 2006; Fandel and Stammen-Hegene, 2006; Fleischhacker and Zhao, 2011; Ho et al., 2006; Mehrotra et al., 2011; Mula et al., 2008; Shaikh et al., 2011; Taskin and Uenal, 2009; Wu et al., 2010), and in the total production costs (Boudia et al., 2008; Fleischhacker and Zhao, 2011; Liu et al., 2007; Mohan et al., 2012; Mula et al., 2008; Pastor et al., 2009; Peidro et al., 2010; Stadtler and Sahling, 2013; van den Heuvel et al., 2007). Other benefits corresponding to other performance measurements, such as 
customer service levels (Denton et al., 2006; Mula et al., 2008; Nourelfath, 2011; Peidro et al., 2010; Shaikh et al., 2011), total setup costs (Fleischhacker and Zhao, 2011; Ho et al., 2006; Mehrotra et al., 2011), production throughput (Chen et al., 2010; Fandel and Stammen-Hegene, 2006) and total transport costs (Taskin and Uenal, 2009; Wu et al., 2010), are also identified in the reviewed works. Several references report the different extensions added to the standard production planning or lot sizing models, such as cellular manufacturing design (Ahkioon et al., 2009; Safaei and Tavakkoli-Moghaddam, 2009), different quality levels in products (Denizel et al., 2010; Ferguson et al., 2009) or the inclusion of subcontracting activities (Merzifonluoglu et al., 2007; Safaei and Tavakkoli-Moghaddam, 2009). Moreover, the capability of extending their proposed models is emphasized by Li and Meissner (2011) and Stadtler (2011). According to several authors, other extensions relate to the consideration of non zero lead times (Grubbstrom and Huynh, 2006a; Safaei and Tavakkoli-Moghaddam, 2009), maintenance activities (Aghezzaf et al., 2007), and capacity decisions and overtime production (Merzifonluoglu et al., 2007). Finally, demand benefits are identified in relation to considering customer preferences by either using flexible or alternative BOM (Lin et al., 2009; Ram et al., 2006) or including marketing and pricing decisions (Barba-Gutierrez et al., 2008; Merzifonluoglu et al., 2007) or demand priorities (Denton et al., 2006).

The other benefits identified in the reviewed papers relate to their application in real-world firms (25 references) and to incorporating uncertainty into the input parameters inherent to real production environments (22 references).

Table 20. Main benefits of the reviewed works

\begin{tabular}{clc}
\hline Type & Benefits & References \\
\hline Solution method & Solution quality/procedure & 187 \\
(205 references) & Robustness & 11 \\
& Flexibility & 7 \\
\hline & Inventory levels/costs & 10 \\
& Total production costs & 9 \\
Improvements & Customer service levels & 5 \\
(31 references) & Setup costs & 3 \\
& Throughput & 2 \\
& Transport costs & 2 \\
\hline Application & Application in real environments & 25 \\
\hline Uncertainty & Uncertain parameters considered & 22 \\
\hline & Cellular design & 2 \\
Extensions & Quality levels in products & 2 \\
(12 references) & Subcontracting activities & 2 \\
& Non-zero lead times & 2 \\
& Capability to extend & 2 \\
& Other extensions & 2 \\
\hline Demand & Customer preferences & 2 \\
(5 references) & Other demand benefits & 3 \\
\hline
\end{tabular}

\section{Discussion}

After reviewing the selected papers on tactical production planning, this section provides some relevant streams and limitations in the literature on tactical production planning. In line with this, we confirm that, despite its importance and impact on existing production systems (Mabert, 2007) and the existence of numerous previous scientific papers, such as Benton and Whybark (1982), Billington et al. (1983), Bobko and Whybark (1985), Grubbström and Molinder (1994, 1996), Grubbström and Ovrin (1992), Grubbström (1999) and Whybark and Williams (1976), among others, very few works have been conducted within the MRP theory framework during 
the study period. Most of the reviewed papers that deal with parts and raw materials planning correspond to multi-level lot-sizing modeling approaches. Generally, these papers focus mainly on developing efficient algorithms for typical lot-sizing extensions, such as inclusion of backlogs, setup times, sequence-dependent setups, etc. In this sense, the main contribution of the reviewed articles is to propose efficient solution methods which outperform previous procedures in the literature in terms of CPU time or optimality or production, inventory, setups or transport costs. The trade-off between efficient solution procedures and the modelling of realistic production systems is reflected in limitations related to production system (e.g., singlemachine, setups, lead times), demand issues (e.g., backorders, lost sales, selling prices or discounts), capacities of the available resources and structure and number of products (e.g., multi-product models, multi-level BOM) that are neglected in order to reduce the computation times and improve the solution process. Despite that, multi-item big-bucket models are majority with respect to single-item models, but mono-level BOM is more common. Moreover, most of the reviewed articles consider capacity constraints related to productive resources and inventory space. On the other hand, the consideration of uncertain parameters related to unpredicted and variable production environments is an additional improvement in the proposed models. However, these parameters have been mainly modeled, especially uncertain demand, with stochastic models. In this case, when statistical data are unreliable or even unavailable, stochastic models may not be the best approach and fuzzy mathematical programming stands as an alternative modelling approach, but only has been considered in 7 of the reviewed papers. In our opinion, and independently of the production area, the reviewed articles address, but do not model, the situations related to current complex industrial environments and their impact on tactical decisions, such as the markets characterized by low demand and high competition, environmental aspects, offshoring of suppliers and importance of transport, etc. Instead, different extensions can be identified in the analyzed papers in addition to those cited above, for example, the consideration of production times (overtime, undertime and subcontracting), multiple and parallel machines and remanufacturing activities and quality issues. Among them, extensions related to demand and setup properties are those more included in the reviewed models. Nevertheless, we find such modeling efforts to reproduce real-world production problems relating to specific production sectors (examples can be found in the references of Table 17).

Although a considerable number of articles has been validated using data from real-world manufacturing firms, most of the reviewed articles perform numerical experiments with random created instances. With respect to the application industry, the automobile industry and the consumer goods industry have the main number of references. Moreover, although some proposals have been validated in real environments, very few of the proposed models are reported to be implemented and incorporated into the planning systems of the companies considered. We believe that this confirms a gap between academic research and industry. In general, industrial practitioners look for tools whose general purpose is to solve production problems easily without having to learn new modeling or programming languages. However, the reviewed articles focus on addressing production planning with problem-dependent solution methods based mainly on operations research principles and programming languages. Mathematical programming-based solution procedures and specific solution methods such as heuristic algorithms are proposed in most of the analyzed papers, and in a lesser extent metaheuristics. These solution approaches can be implemented by using modeling languages (e.g., Lingo, OPL, AMPL, GAMS, MATLAB), programming languages (e.g., C, Java, Delphi) or commercial solvers such as CPLEX or Xpress-MP, or combinations between them. The need to obtain optimal or near to optimal results makes the option of using a powerful tool such as CPLEX (in isolation or combined with other tools) becomes most frequent. This can prove a great difficulty for SMEs which cannot afford to buy these expensive, specific tools or to hire specialists in these fields. From our point of view, production planning models that reflect the current problems in complex industrial production environments are needed. These models should be solved with highly customizable and easy-to-use tools that integrate into firm's current information systems (ERP, APS, etc.) in order to bridge this gap. 
This research presents some limitations. First, the obtained results and findings are based on articles collected from 36 relevant operations research and management journals from Barman et al.'s (2001) ranking, and the 3rd and 4th levels from the ABS Academic Journal Quality Guide in the Operations, Technology and Management, and Operations Research and Management Science subjects. Other journals, which could cover production planning problems from a simulation or mathematical applied perspective, for example, are not considered. Moreover, based on the works of Chaudhry and Luo (2005) and of Wong and Lai (2011), we review only journal articles, hence conference proceedings and doctoral dissertations are not considered by assuming their subsequent publication in high-quality research journals. On the other hand, it is important to highlight new trends appeared recently in the literature, as sustainability, green production planning, or production planning with carbon emissions (Ashby et al., 2012; Brandenburg et al., 2014; Chaabane et al., 2012; Deif, 2011; Elhedhli and Merrick, 2012; Kenneth et al., 2012; Seuring, 2013; Sundarakani et al., 2010) have not been considered along this paper. Furthermore, given the aggregated presentation of the information, references may appear in more than one product within each classification criterion in many cases. Finally, only minority references are cited in each category as it is impossible to provide details of each one due to limited space. For this reason, the extended tables with each reference are available by clicking on the following link:

http://personales.upv.es/fcodiama/review/discretetime\%20models\%20for\%20tactical\%20production\%20planning.pdf

\section{Conclusions}

This work surveys 250 articles related to tactical planning in relevant operations research and management journals. To study the analyzed works, a classification based on the analysis of the following aspects is proposed: problem type, aim, number of products, time period, nature of demand, capacities constraints, extensions, modeling approach, solution approach, development tool, application, limitations and benefits. The main findings are summarized as follows: (1) most of the reviewed tactical production planning articles address master production scheduling problems; (2) multi-product big bucket production planning models are more prevalent, especially with mono-level product structures; (3) most of the limited resources considered in the reviewed papers correspond to productive resources and, to a lesser extent, to inventory capacities; (4) the inclusion of backlogs or backorders, setup times, parallel machines, overtime capacities, and the consideration of network-type multi-site configuration, stand out in terms of extensions; (5) the most widely used modeling approach is linear/integer/mixed integer linear programming; (6) exact algorithms, such as branch-and-bound in commercial MIP solvers, are the most widely used, followed by specific solution methods, such as tailored algorithms or hierarchical and simulation frameworks; (7) CPLEX, C and its variants and Lindo/Lingo are the most popular development tools among solvers, programming languages and modeling languages, respectively; (8) a small number of works has been validated in real production environments, of which the most outstanding are the sawmills, wood and furniture, automobile and semiconductors and electronic devices industries; (9) the most relevant criterion pointed by authors to evaluate the benefits and limitations of their works is the quality of the solution obtained in terms of optimality, the time needed, or the improvements made to previous solution procedures.

After conducting this review, we indicate some gaps in the literature with some proposed future research lines: (1) it is important to underline that we found no work that examines multi-level tactical production problems by considering not only the existence of near and offshore suppliers of parts and components, but also the impact that procurement transport may involve on accomplishing production plans. In this sense, like Mula et al. (2010a), we can confirm the need for optimization models and tools for the production and procurement transport planning processes which contemplate different forms of long- and short-distance transport (railway, air, full truck load, grouping, milk round, routes, etc.) and different characteristics (legal or 
environmental restrictions). In this sense, we refer readers to Díaz-Madroñero et al. (2012) and Mula et al. (2012) for some conceptual models. Analytical models based on these conceptual models are a forthcoming work; (2) growing customer requests and increasing competition make demand management an important part of the success and applicability of tactical production planning models. Thus, consideration of demand-driven tools and mass customization practices can be an important extension to bear in mind; (3) applying tactical planning models in real-world production environments in which uncertain conditions can also be considered; (4) real-world industrial problems often have several conflicting objectives. Thus, modeling realistic tactical production planning problem implies the use of multi-objective programming, which can deal with the trade-off among the conflicting goals; (5) studying solution approaches, such as mathematical programming optimization, metaheuristics and/or matheuristics, which deal with the complexities associated with the extensions identified in this work and previous gaps; (6) integration of these models with companies' information systems.

\section{Acknowledgment}

This work has been funded by the Universitat Politècnica de València projects: 'Material Requirement Planning Fourth Generation (MRPIV)' (Ref. PAID-05-12) and 'Quantitative Models for the Design of Socially Responsible Supply Chains under Uncertainty Conditions. Application of Solution Strategies based on Hybrid Metaheuristics' (PAID-06-12).

\section{References}

Absi, N., Kedad-Sidhoum, S., 2008. The multi-item capacitated lot-sizing problem with setup times and shortage costs. EUROPEAN JOURNAL OF OPERATIONAL RESEARCH 185, 1351-1374.

Absi, N., Kedad-Sidhoum, S., Dauzere-Peres, S., 2011. Uncapacitated lot-sizing problem with production time windows, early productions, backlogs and lost sales. INTERNATIONAL JOURNAL OF PRODUCTION RESEARCH 49, 2551-2566.

Adams, F.P., Cox, J.F., 1985. Manufacturing resource planning: An information systems model. Long Range Planning 18, 86-92.

Aghezzaf, E.-H., 2007. Production planning and warehouse management in supply networks with inter-facility mold transfers. EUROPEAN JOURNAL OF OPERATIONAL RESEARCH 182, 1122-1139.

Aghezzaf, E.H., Jamali, M.A., Ait-Kadi, D., 2007. An integrated production and preventive maintenance planning model. EUROPEAN JOURNAL OF OPERATIONAL RESEARCH 181, 679-685.

Aghezzaf, E.-H., Sitompul, C., Najid, N.M., 2010. Models for robust tactical planning in multistage production systems with uncertain demands. COMPUTERS \& OPERATIONS RESEARCH 37, 880-889.

Aghezzaf, E.-H., Sitompul, C., Van den Broecke, F., 2011. A robust hierarchical production planning for a capacitated two-stage production system. COMPUTERS \& INDUSTRIAL ENGINEERING 60, 361-372.

Ahkioon, S., Bulgak, A.A., Bektas, T., 2009. Cellular manufacturing systems design with routing flexibility, machine procurement, production planning and dynamic system reconfiguration. INTERNATIONAL JOURNAL OF PRODUCTION RESEARCH 47, 1573-1600.

Akartunali, K., Miller, A.J., 2009. A heuristic approach for big bucket multi-level production planning problems. EUROPEAN JOURNAL OF OPERATIONAL RESEARCH 193, 396-411.

Akbalik, A., Penz, B., 2009. Exact methods for single-item capacitated lot sizing problem with alternative machines and piece-wise linear production costs. INTERNATIONAL JOURNAL OF PRODUCTION ECONOMICS 119, 367-379. 
Akbalik, A., Penz, B., 2011. Comparison of just-in-time and time window delivery policies for a single-item capacitated lot sizing problem. INTERNATIONAL JOURNAL OF PRODUCTION RESEARCH 49, 2567-2585.

Akbalik, A., Pochet, Y., 2009. Valid inequalities for the single-item capacitated lot sizing problem with step-wise costs. EUROPEAN JOURNAL OF OPERATIONAL RESEARCH 198, 412-434.

Aksen, D., 2007. Loss of customer goodwill in the uncapacitated lot-sizing problem. COMPUTERS \& OPERATIONS RESEARCH 34, 2805-2823.

Al-Ameri, T.A., Shah, N., Papageorgiou, L.G., 2008. Optimization of vendor-managed inventory systems in a rolling horizon framework. COMPUTERS \& INDUSTRIAL ENGINEERING 54, 1019-1047.

Albey, E., Bilge, U., 2011. A hierarchical approach to FMS planning and control with simulation-based capacity anticipation. INTERNATIONAL JOURNAL OF PRODUCTION RESEARCH 49, 3319-3342.

Almada-Lobo, B., James, R.J.W., 2010. Neighbourhood search meta-heuristics for capacitated lot-sizing with sequence-dependent setups. INTERNATIONAL JOURNAL OF PRODUCTION RESEARCH 48, 861-878.

Almada-Lobo, B., Klabjan, D., Carravilla, M.A., Oliveira, J.F., 2007. Single machine multiproduct capacitated lot sizing with sequence-dependent setups. INTERNATIONAL JOURNAL OF PRODUCTION RESEARCH 45, 4873-4894.

Almada-Lobo, B., Oliveira, J.F., Carravilla, M.A., 2008. Production planning and scheduling in the glass container industry: A VNS approach. INTERNATIONAL JOURNAL OF PRODUCTION ECONOMICS 114, 363-375.

Almeder, C., 2010. A hybrid optimization approach for multi-level capacitated lot-sizing problems. EUROPEAN JOURNAL OF OPERATIONAL RESEARCH 200, 599-606.

Almeder, C., Preusser, M., Hartl, R.F., 2009. Simulation and optimization of supply chains: alternative or complementary approaches? OR SPECTRUM 31, 95-119.

Alonso-Ayuso, A., Escudero, L.F., Garín, A., Ortuño, M. T. and Pérez, G., 2003. An Approach for Strategic Supply Chain Planning under Uncertainty based on Stochastic 0- 1 Programming. JOURNAL OF GLOBAL OPTIMIZATION 26(1), 97-124.

Aloulou, M.A., Dolgui, A. \& Kovalyov, M.Y., 2013. A bibliography of non-deterministic lotsizing models. INTERNATIONAL JOURNAL OF PRODUCTION RESEARCH, 0(0), pp.1-18. DOI: 10.1080/00207543.2013.855336

Alwan, L.C., Liu, J.J., Yao, D.-Q., 2008. Forecast facilitated lot-for-lot ordering in the presence of autocorrelated demand. COMPUTERS \& INDUSTRIAL ENGINEERING 54, 840850.

Anily, S., Tzur, M., Wolsey, L.A., 2009. Multi-item lot-sizing with joint set-up costs. MATHEMATICAL PROGRAMMING 119, 79-94.

Anthony, R.N., 1965. Planning and control systems: a framework for analysis. Division of Research, Graduate School of Business Administration, Harvard University.

Armentano, V.A., Shiguemoto, A.L., Lokketangen, A., 2011. Tabu search with path relinking for an integrated production-distribution problem. COMPUTERS \& OPERATIONS RESEARCH 38, 1199-1209.

Ashby, A., Leat, M., Hudson-Smith, M., 2012. Making connections: a review of supply chain management and sustainability literature. SUPPLY CHAIN MANAGEMENT: AN INTERNATIONAL JOURNAL 17, 497-516.

Asmundsson, J., Rardin, R.L., Turkseven, C.H., Uzsoy, R., 2009. Production Planning with Resources Subject to Congestion. NAVAL RESEARCH LOGISTICS 56, 142-157.

Azaron, A., Tang, O., Tavakkoli-Moghaddam, R., 2009. Dynamic lot sizing problem with continuous-time Markovian production cost. INTERNATIONAL JOURNAL OF PRODUCTION ECONOMICS 120, 607-612.

Baptiste, P., Alsene, E., Gaudimier, R., 2008. Integration of production and shipping planning: a co-operative approach. PRODUCTION PLANNING \& CONTROL 19, 645-654. 
Barba-Gutierrez, Y., Adenso-Diaz, B., Gupta, S.M., 2008. Lot sizing in reverse MRP for scheduling disassembly. INTERNATIONAL JOURNAL OF PRODUCTION ECONOMICS 111, 741-751.

Bard, J.F., Nananukul, N., 2009. The integrated production-inventory-distribution-routing problem. JOURNAL OF SCHEDULING 12, 257-280.

Barman, S., Hanna, M.D., LaForge, R.L., 2001. Perceived relevance and quality of POM journals: a decade later. Journal of Operations Management 19, 367-385.

Beamon, B.M., Chen, V.C.P., 2001. Performance analysis of conjoined supply chains. International Journal of Production Research 39, 3195-3218.

Begnaud, J., Benjaafar, S., Miller, L.A., 2009. The multi-level lot sizing problem with flexible production sequences. IIE TRANSACTIONS 41, 702-715.

Benton, W.C., Whybark, D.C., 1982. Material requirements planning (MRP) and purchase discounts. Journal of Operations Management 2, 137-143.

Berk, E., Toy, A.O., Hazir, O., 2008. Single item lot-sizing problem for a warm/cold process with immediate lost sales. EUROPEAN JOURNAL OF OPERATIONAL RESEARCH 187, 1251-1267.

Bilgen, B., Guenther, H.-O., 2010. Integrated production and distribution planning in the fast moving consumer goods industry: a block planning application. OR SPECTRUM 32, 927-955.

Billington, P.J., McClain, J.O., Thomas, L.J., 1983. Mathematical programming approaches to capacity-constrained MRP systems: Review, formulation and problem reduction. Management Science 29, 1126-1141.

Biswas, S., Narahari, Y., 2004. Object oriented modeling and decision support for supply chains. European Journal of Operational Research 153, 704-726.

Bitran, G.R., Haas, E.A., Hax, A.C., 1981. Hierarchical Production Planning: A Single Stage System. Operations Research 29, 717-743.

Bjork, K.-M., Carlsson, C., 2007. The effect of flexible lead times on a paper producer. INTERNATIONAL JOURNAL OF PRODUCTION ECONOMICS 107, 139-150.

Bobko, P.B., Whybark, D.C., 1985. The Coefficient of Variation as a Factor in Mrp Research. Decision Sciences 16, 420-427.

Bogataj, L., Bogataj, M., 2007. The study of optimal additional investments in capacities for reduction of delays in value chain. INTERNATIONAL JOURNAL OF PRODUCTION ECONOMICS 108, 281-290.

Bollapragada, R., Della Croce, F., Ghirardi, M., 2011. Discrete-time, economic lot scheduling problem on multiple, non-identical production lines. EUROPEAN JOURNAL OF OPERATIONAL RESEARCH 215, 89-96.

Bouchriha, H., Ouhimmou, M., D’Amours, S., 2007. Lot sizing problem on a paper machine under a cyclic production approach. INTERNATIONAL JOURNAL OF PRODUCTION ECONOMICS 105, 318-328.

Boudia, M., Louly, M.A.O., Prins, C., 2007. A reactive GRASP and path relinking for a combined production-distribution problem. COMPUTERS \& OPERATIONS RESEARCH 34, 3402-3419.

Boudia, M., Louly, M.A.O., Prins, C., 2008. Fast heuristics for a combined production planning and vehicle routing problem. PRODUCTION PLANNING \& CONTROL 19, 85-96.

Boudia, M., Prins, C., 2009. A memetic algorithm with dynamic population management for an integrated production-distribution problem. EUROPEAN JOURNAL OF OPERATIONAL RESEARCH 195, 703-715.

Brahimi, N., Dauzere-Peres, S., Najid, N.M., 2006a. Capacitated multi-item lot-sizing problems with time windows. OPERATIONS RESEARCH 54, 951-967.

Brahimi, N., Dauzere-Peres, S., Najid, N.M., Nordli, A., 2006b. Single item lot sizing problems. EUROPEAN JOURNAL OF OPERATIONAL RESEARCH, 168(1), pp.1-16.

Brahimi, N., Dauzere-Peres, S., Wolsey, L.A., 2010. Polyhedral and Lagrangian approaches for lot sizing with production time windows and setup times. COMPUTERS \& OPERATIONS RESEARCH 37, 182-188. 
Brandenburg, M., Govindan, K., Sarkis, J., Seuring, S., 2014. Quantitative models for sustainable supply chain management: Developments and directions. EUROPEAN JOURNAL OF OPERATIONAL RESEARCH 233, 299-312.

Brandimarte, P., 2006. Multi-item capacitated lot-sizing with demand uncertainty. INTERNATIONAL JOURNAL OF PRODUCTION RESEARCH 44, 2997-3022.

Buschkuehl, L., Sahling, F., Helber, S., Tempelmeier, H., 2010. Dynamic capacitated lot-sizing problems: a classification and review of solution approaches. OR SPECTRUM 32, 231261.

Buschkühl, L., Sahling, F., Helber, S., Tempelmeier, H., 2010. Dynamic capacitated lot-sizing problems: a classification and review of solution approaches. OR Spectrum 32, 231261.

Černý, V., 1985. Thermodynamical approach to the traveling salesman problem: An efficient simulation algorithm. J Optim Theory Appl 45, 41-51.

Chaabane, A., Ramudhin, A., Paquet, M., 2012. Design of sustainable supply chains under the emission trading scheme. INTERNATIONAL JOURNAL OF PRODUCTION ECONOMICS 135, 37-49.

Chand, S., Hsu, V.N., Sethi, S., Deshpande, V., 2007. A dynamic lot sizing problem with multiple customers: customer-specific shipping and backlogging costs. IIE TRANSACTIONS 39, 1059-1069.

Chaudhry, S.S., Luo, W., 2005. Application of genetic algorithms in production and operations management: a review. International Journal of Production Research 43, 4083-4101.

Cheaitou, A., Van Delft, C., Dallery, Y., Jemai, Z., 2009. Two-period production planning and inventory control. INTERNATIONAL JOURNAL OF PRODUCTION ECONOMICS $118,118-130$.

Chen, M., Sarin, S.C., Peake, A., 2010. Integrated lot sizing and dispatching in wafer fabrication. PRODUCTION PLANNING \& CONTROL 21, 485-495.

Chen, S.-P., Huang, W.-L., 2010. A membership function approach for aggregate production planning problems in fuzzy environments. INTERNATIONAL JOURNAL OF PRODUCTION RESEARCH 48, 7003-7023.

Christou, I.T., Lagodimos, A.G., Lycopoulou, D., 2007. Hierarchical production planning for multi-product lines in the beverage industry. PRODUCTION PLANNING \& CONTROL 18, 367-376.

Christou, I.T., Ponis, S., 2009. A hierarchical system for effective coordination of available-topromise logic mechanisms. INTERNATIONAL JOURNAL OF PRODUCTION RESEARCH 47, 3063-3078.

Chung-Yee Lee, Çetinkaya, S., Wagelmans, A.P.M., 2001. A Dynamic Lot-Sizing Model with Demand Time Windows. Management Science 47, 1384-1395.

Clark, A.R., Morabito, R., Toso, E.A.V., 2010. Production setup-sequencing and lot-sizing at an animal nutrition plant through atsp subtour elimination and patching. JOURNAL OF SCHEDULING 13, 111-121.

Comelli, M., Gourgand, M., Lemoine, D., 2008. A review of tactical planning models. J. Syst. Sci. Syst. Eng. 17, 204-229.

Cowdrick, R.M., 1995. Supply chain planning (SCP) - Concepts and case studies. Computers \& Industrial Engineering 29, 245-248.

Cristobal, M.P., Escudero, L.F., Monge, J.F., 2009. On stochastic dynamic programming for solving large-scale planning problems under uncertainty. COMPUTERS \& OPERATIONS RESEARCH 36, 2418-2428.

Czyzyk, J., Mesnier, M.P., Moré, J.J., 1998. The NEOS server. Computational Science \& Engineering, IEEE 5, 68-75.

De Araujo, S.A., Arenales, M.N., Clark, A.R., 2008. Lot sizing and furnace scheduling in small foundries. COMPUTERS \& OPERATIONS RESEARCH 35, 916-932.

Defersha, F.M., Chen, M., 2008. A linear programming embedded genetic algorithm for an integrated cell formation and lot sizing considering product quality. EUROPEAN JOURNAL OF OPERATIONAL RESEARCH 187, 46-69. 
Degraeve, Z., Jans, R., 2007. A new dantzig-wolfe reformulation and branch-and-price algorithm for the capacitated lot-sizing problem with setup times. OPERATIONS RESEARCH 55, 909-920.

Deif, A.M., 2011. A system model for green manufacturing. JOURNAL OF CLEANER PRODUCTION 19, 1553-1559.

Demirli, K., Yimer, A.D., 2008. Fuzzy scheduling of a build-to-order supply chain. INTERNATIONAL JOURNAL OF PRODUCTION RESEARCH 46, 3931-3958.

Deng, S., Yano, C., 2006. Joint production and pricing decisions with setup costs and capacity constraints. MANAGEMENT SCIENCE 52, 741-756.

Denizel, M., Ferguson, M., Souza, G. “Gil” C., 2010. Multiperiod Remanufacturing Planning With Uncertain Quality of Inputs. IEEE TRANSACTIONS ON ENGINEERING MANAGEMENT 57, 394-404.

Denizel, M., Sural, H., 2006. On alternative mixed integer programming formulations and LPbased heuristics for lot-sizing with setup times. JOURNAL OF THE OPERATIONAL RESEARCH SOCIETY 57, 389-399.

Denton, B.T.|, Forrest, J., Milne, R.J., 2006. IBM solves a mixed-integer program to optimize its semiconductor supply chain. INTERFACES 36, 386-399.

Depuy, G.W., Usher, J.S., Walker, R.L., Taylor, G.D., 2007. Production planning for remanufactured products. PRODUCTION PLANNING \& CONTROL 18, 573-583.

Díaz-Madroñero, M., Mula, J. \& Peidro, D., 2012. A Conceptual Model for MRP IV. En J. E. Hernández et al., eds. Decision Support Systems - Collaborative Models and Approaches in Real Environments. Lecture Notes in Business Information Processing. Springer Berlin Heidelberg, pp. 14-25

Dolgui, A., Ammar, O. B., Hnaien, F., \& Louly, M. A., 2013. A state of the art on supply planning and inventory control under lead time uncertainty. STUDIES IN INFORMATICS AND CONTROL, 22(3), pp.255-268.

Dolgui, A. \& Prodhon, C., 2007. Supply planning under uncertainties in MRP environments: A state of the art. ANNUAL REVIEWS IN CONTROL, 31(2), pp.269-279.

Dorigo, M., Maniezzo, V., Colorni, A., 1996. Ant system: optimization by a colony of cooperating agents. Systems, Man, and Cybernetics, Part B: Cybernetics, IEEE Transactions on 26, 29-41.

Drechsel, J., Kimms, A., 2011. Cooperative lot sizing with transshipments and scarce capacities: solutions and fair cost allocations. INTERNATIONAL JOURNAL OF PRODUCTION RESEARCH 49, 2643-2668.

Dudek, G., Stadtler, H., 2007. Negotiation-based collaborative planning in divergent two-tier supply chains. INTERNATIONAL JOURNAL OF PRODUCTION RESEARCH 45, 465-484.

Eksioglu, S., Romeijn, H., Pardalos, P., 2006. Cross-facility management of production and transportation planning problem. COMPUTERS \& OPERATIONS RESEARCH 33, 3231-3251.

Eksioglu, S.D., Eksioglu, B., Romeijn, H.E., 2007. A Lagrangian heuristic for integrated production and transportation planning problems in a dynamic, multi-item, two-layer supply chain. IIE TRANSACTIONS 39, 191-201.

Elhedhli, S., Merrick, R., 2012. Green supply chain network design to reduce carbon emissions. TRANSPORTATION RESEARCH PART D: TRANSPORT AND ENVIRONMENT 17, 370-379.

Erromdhani, R., Eddaly, M. \& Rebai, A., 2012. Hierarchical production planning with flexibility in agroalimentary environment: a case study. JOURNAL OF INTELLIGENT MANUFACTURING, 23(3), pp.811-819.

Fandel, G., Stammen-Hegene, C., 2006. Simultaneous lot sizing and scheduling for multiproduct multi-level production. INTERNATIONAL JOURNAL OF PRODUCTION ECONOMICS 104, 308-316.

Fazle Baki, M., Chaouch, B.A. \& Abdul-Kader, W., 2014. A heuristic solution procedure for the dynamic lot sizing problem with remanufacturing and product recovery. COMPUTERS \& OPERATIONS RESEARCH, 43, pp.225-236. 
Federgruen, A., Meissner, J., Tzur, M., 2007. Progressive interval heuristics for multi-item capacitated lot-sizing problems. OPERATIONS RESEARCH 55, 490-502.

Feng, Y., Chen, S., Kumar, A., Lin, B., 2011. Solving single-product economic lot-sizing problem with non-increasing setup cost, constant capacity and convex inventory cost in $\mathrm{O}(\mathrm{N} \log \mathrm{N})$ time. COMPUTERS \& OPERATIONS RESEARCH 38, 717-722.

Feng, Y., D’Amours, S., Beauregard, R., 2008. The value of sales and operations planning in oriented strand board industry with make-to-order manufacturing system: Cross functional integration under deterministic demand and spot market recourse. INTERNATIONAL JOURNAL OF PRODUCTION ECONOMICS 115, 189-209.

Feng, Y., D’Amours, S., Beauregard, R., 2010. Simulation and performance evaluation of partially and fully integrated sales and operations planning. INTERNATIONAL JOURNAL OF PRODUCTION RESEARCH 48, 5859-5883.

Feo, T.A., Resende, M.G.C., 1989. A probabilistic heuristic for a computationally difficult set covering problem. Operations research letters 8, 67-71.

Ferguson, M., Guide, Jr., V.D., Koca, E., Souza, G.C., 2009. The Value of Quality Grading in Remanufacturing. PRODUCTION AND OPERATIONS MANAGEMENT 18, 300314.

Ferreira, D., Morabito, R., Rangel, S., 2009. Solution approaches for the soft drink integrated production lot sizing and scheduling problem. EUROPEAN JOURNAL OF OPERATIONAL RESEARCH 196, 697-706.

Ferreira, D., Morabito, R., Rangel, S., 2010. Relax and fix heuristics to solve one-stage onemachine lot-scheduling models for small-scale soft drink plants. COMPUTERS \& OPERATIONS RESEARCH 37, 684-691.

Fleischhacker, A.J., Zhao, Y., 2011. Planning for demand failure: A dynamic lot size model for clinical trial supply chains. EUROPEAN JOURNAL OF OPERATIONAL RESEARCH 211, 496-506.

Gaglioppa, F., Miller, L.A., Benjaafar, S., 2008. Multitask and multistage production planning and scheduling for process industries. OPERATIONS RESEARCH 56, 1010-1025.

Galasso, F., Merce, C., Grabot, B., 2009. Decision support framework for supply chain planning with flexible demand. INTERNATIONAL JOURNAL OF PRODUCTION RESEARCH 47, 455-478.

Genin, P., Lamouri, S., Thomas, A., 2008. Multi-facilities tactical planning robustness with experimental design. PRODUCTION PLANNING \& CONTROL 19, 171-182.

Geunes, J., Romeijn, H., Taaffe, K., 2006. Requirements planning with pricing and order selection flexibility. OPERATIONS RESEARCH 54, 394-401.

Gicquel, C., Miegeville, N., Minoux, M., Dallery, Y., 2009. Discrete lot sizing and scheduling using product decomposition into attributes. COMPUTERS \& OPERATIONS RESEARCH 36, 2690-2698.

Glover, F., 1989. Tabu search-part I. ORSA Journal on computing 1, 190-206.

Glover, F., 1990. Tabu search-part II. ORSA Journal on computing 2, 4-32.

Glover, F., 1998. A template for scatter search and path relinking, in: Artificial Evolution. Springer, pp. 1-51.

Glover, F., Laguna, M., Martí, R., 2000. Fundamentals of scatter search and path relinking. Control and cybernetics 39, 653-684.

Glover, F., McMillan, C., 1986. The general employee scheduling problem. An integration of MS and AI. Computers \& operations research 13, 563-573.

Gonzalez-Ramirez, R.G., Smith, N.R., Askin, R.G., 2011. A heuristic approach for a multiproduct capacitated lot-sizing problem with pricing. INTERNATIONAL JOURNAL OF PRODUCTION RESEARCH 49, 1173-1196.

Goren, H.G., Tunali, S. \& Jans, R., 2012. A hybrid approach for the capacitated lot sizing problem with setup carryover. INTERNATIONAL JOURNAL OF PRODUCTION RESEARCH, 50(6), pp.1582-1597.

Gramani, M.C.N., Franca, P.M., 2006. The combined cutting stock and lot-sizing problem in industrial processes. EUROPEAN JOURNAL OF OPERATIONAL RESEARCH 174, 509-521. 
Gramani, M.C.N., Franca, P.M., Arenales, M.N., 2009. A Lagrangian relaxation approach to a coupled lot-sizing and cutting stock problem. INTERNATIONAL JOURNAL OF PRODUCTION ECONOMICS 119, 219-227.

Grosfeld-Nir, A. \& Gerchak, Y., 2004. Multiple Lotsizing in Production to Order with Random Yields: Review of Recent Advances. ANNALS OF OPERATIONS RESEARCH, 126(1-4), pp.43-69.

Gropp, W., Moré, J., 1997. Optimization environments and the NEOS server. Approximation Theory and Optimization 167-182.

Grubbstrom, R., Huynh, T., 2006a. Multi-level, multi-stage capacity-constrained productioninventory systems in discrete time with non-zero lead times using MRP theory. INTERNATIONAL JOURNAL OF PRODUCTION ECONOMICS 101, 53-62.

Grubbström, R.W., 1999. A net present value approach to safety stocks in a multi-level MRP system. International Journal of Production Economics 59, 361-375.

Grubbstrom, R.W., Huynh, T.T.T., 2006b. Analysis of standard ordering policies within the framework of MRP theory. INTERNATIONAL JOURNAL OF PRODUCTION RESEARCH 44, 3759-3773.

Grubbström, R.W., Molinder, A., 1994. Further theoretical considerations on the relationship between MRP, input-output analysis and multi-echelon inventory systems. International Journal of Production Economics 35, 299-311.

Grubbström, R.W., Molinder, A., 1996. Safety production plans in MRP-systems using transform methodology. International Journal of Production Economics 46-47, 297309.

Grubbström, R.W., Ovrin, P., 1992. Intertemporal generalization of the relationship between material requirements planning and input-output analysis. International Journal of Production Economics 26, 311-318.

Guan, Y., Ahmed, S., Nemhauser, G.L., 2009. Cutting Planes for Multistage Stochastic Integer Programs. OPERATIONS RESEARCH 57, 287-298.

Guan, Y., Miller, A.J., 2008. Polynomial-Time Algorithms for Stochastic Uncapacitated LotSizing Problems. OPERATIONS RESEARCH 56, 1172-1183.

Guan, Z., Philpott, A.B., 2011. A multistage stochastic programming model for the New Zealand dairy industry. International Journal of Production Economics 134, 289-299.

Guide Jr, V.D.R., Van Wassenhove, L.N., 2002. The reverse supply chain. Harvard Business Review 80, 25-26.

Gunnarsson, H., Ronnqvist, M., 2008. Solving a multi-period supply chain problem for a pulp company using heuristics-An application to Sodra Cell AB. INTERNATIONAL JOURNAL OF PRODUCTION ECONOMICS 116, 75-94.

Gupta, A., Maranas, C.D., 1999. A Hierarchical Lagrangian Relaxation Procedure for Solving Midterm Planning Problems. INDUSTRIAL \& ENGINEERING CHEMISTRY RESEARCH 38(5), 1937-1947.

Gupta, A. and Maranas, C.D., 2003. Managing demand uncertainty in supply chain planning. COMPUTERS \& CHEMICAL ENGINEERING 27(8-9), 1219-1227.

Gupta, A., Maranas, C.D., McDonald, C.M., 2000. Mid-term supply chain planning under demand uncertainty: customer demand satisfaction and inventory management. COMPUTERS \& CHEMICAL ENGINEERING 24, 2613-2621.

Gutierrez, J., Sedeno-Noda, A., Colebrook, M., Sicilia, J., 2008. An efficient approach for solving the lot-sizing problem with time-varying storage capacities. EUROPEAN JOURNAL OF OPERATIONAL RESEARCH 189, 682-693.

Haugen, K.K., Olstad, A., Pettersen, B.I., 2007. The profit maximizing capacitated lot-size (PCLSP) problem. EUROPEAN JOURNAL OF OPERATIONAL RESEARCH 176, 165-176.

HAX, A., 1975. AGGREGATE PRODUCTION PLANNING. Oper. Res. 23, B368-B368.

Hax, A.C., Meal, H.C., 1973. Hierarchical integration of production planning and scheduling. DTIC Document. 
Helber, S., Sahling, F., 2010. A fix-and-optimize approach for the multi-level capacitated lot sizing problem. INTERNATIONAL JOURNAL OF PRODUCTION ECONOMICS 123, 247-256.

Ho, J.C., Chang, Y.-L., Solis, A.O., 2006. Two modifications of the least cost per period heuristic for dynamic lot-sizing. JOURNAL OF THE OPERATIONAL RESEARCH SOCIETY 57, 1005-1013.

Ho, J.C., Solis, A.O., Chang, Y.-L., 2007. An evaluation of lot-sizing heuristics for deteriorating inventory in material requirements planning systems. COMPUTERS \& OPERATIONS RESEARCH 34, 2562-2575.

Holland, J.H., 1975. Adaptation in natural and artificial systems: an introductory analysis with applications to biology, control, and artificial intelligence. University of Michigan Press.

Hsu, H.-M., Su, T.-S., Wu, M.-C., Huang, L.-C., 2009. Multiple lot-sizing decisions with an interrupted geometric yield and variable production time. COMPUTERS \& INDUSTRIAL ENGINEERING 57, 699-706.

Huh, W.T., Kachani, S., Sadighian, A., 2010. Optimal Pricing and Production Planning for Subscription-Based Products. PRODUCTION AND OPERATIONS MANAGEMENT 19, 19-39.

Hwang, H.-C., 2007. Dynamic lot-sizing model with production time windows. NAVAL RESEARCH LOGISTICS 54, 692-701.

Hwang, H.-C., 2010. Economic Lot-Sizing for Integrated Production and Transportation. OPERATIONS RESEARCH 58, 428-444.

Hwang, H.-C., Jaruphongsa, W., 2008. Dynamic lot-sizing model for major and minor demands. EUROPEAN JOURNAL OF OPERATIONAL RESEARCH 184, 711-724.

Hwang, H.-C., Jaruphongsa, W., Cetinkaya, S., Lee, C.-Y., 2010. Capacitated dynamic lotsizing problem with delivery/production time windows. OPERATIONS RESEARCH LETTERS 38, 408-413.

Ibarra-Rojas, O.J., Ríos-Mercado, R.Z., Rios-Solis, Y.A., Saucedo-Espinosa, M.A., 2011. A decomposition approach for the piece-mold-machine manufacturing problem. International Journal of Production Economics 134, 255-261.

Jamalnia, A., Soukhakian, M.A., 2009. A hybrid fuzzy goal programming approach with different goal priorities to aggregate production planning. COMPUTERS \& INDUSTRIAL ENGINEERING 56, 1474-1486.

James, R.J.W., Almada-Lobo, B., 2011. Single and parallel machine capacitated lotsizing and scheduling: New iterative MIP-based neighborhood search heuristics. COMPUTERS \& OPERATIONS RESEARCH 38, 1816-1825.

Jayaraman, V., 2006. Production planning for closed-loop supply chains with product recovery and reuse: an analytical approach. INTERNATIONAL JOURNAL OF PRODUCTION RESEARCH 44, 981-998.

Jozefowska, J., Zimniak, A., 2008. Optimization tool for short-term production planning and scheduling. INTERNATIONAL JOURNAL OF PRODUCTION ECONOMICS 112, 109-120.

Jung, H., Chen, F.F., Jeong, B., 2008a. Decentralized supply chain planning framework for third party logistics partnership. COMPUTERS \& INDUSTRIAL ENGINEERING 55, 348364.

Jung, H., Jeong, B., Lee, C.-G., 2008b. An order quantity negotiation model for distributordriven supply chains. INTERNATIONAL JOURNAL OF PRODUCTION ECONOMICS 111, 147-158.

Kaczmarczyk, W., 2011. Proportional lot-sizing and scheduling problem with identical parallel machines. INTERNATIONAL JOURNAL OF PRODUCTION RESEARCH 49, 26052623.

Kanyalkar, A.P., Adil, G.K., 2007. Aggregate and detailed production planning integrating procurement and distribution plans in a multi-site environment. INTERNATIONAL JOURNAL OF PRODUCTION RESEARCH 45, 5329-5353. 
Karabuk, S., 2008. Production planning under uncertainty in textile manufacturing. JOURNAL OF THE OPERATIONAL RESEARCH SOCIETY 59, 510-520.

Karimi, B., Fatemi Ghomi, S.M.T., Wilson, J.M., 2003. The capacitated lot sizing problem: a review of models and algorithms. Omega 31, 365-378.

Karimi, B., Ghomi, S., Wilson, J., 2006. A tabu search heuristic for solving the CLSP with backlogging and set-up carry-over. JOURNAL OF THE OPERATIONAL RESEARCH SOCIETY 57, 140-147.

Karni, R., 1981. Integer linear programming formulation of the material requirements planning problem. Journal of Optimization Theory and Applications 35, 217-230.

Kefeli, A., Uzsoy, R., Fathi, Y., Kay, M., 2011. Using a mathematical programming model to examine the marginal price of capacitated resources. INTERNATIONAL JOURNAL OF PRODUCTION ECONOMICS 131, 383-391.

Kennedy, J., Eberhart, R., 1995. Particle swarm optimization, in: , IEEE International Conference on Neural Networks, 1995. Proceedings. Presented at the , IEEE International Conference on Neural Networks, 1995. Proceedings, pp. $1942-1948$ vol.4.

Kenneth W. G., Zelbst, P.J., Meacham, J., Bhadauria, V.S., 2012. Green supply chain management practices: impact on performance. SUPPLY CHAIN MANAGEMENT: AN INTERNATIONAL JOURNAL 17, 290-305.

Kim, H., Lee, D., Xirouchakis, P., 2006. Two-phase heuristic for disassembly scheduling with multiple product types and parts commonality. INTERNATIONAL JOURNAL OF PRODUCTION RESEARCH 44, 195-212.

Kim, H.-J., Xirouchakis, P., 2010. Capacitated disassembly scheduling with random demand. INTERNATIONAL JOURNAL OF PRODUCTION RESEARCH 48, 7177-7194.

Kirkpatrick, S., Gelatt, C.D., Vecchi, M.P., 1983. Optimization by Simulated Annealing. Science 220, 671-680.

Ko, M., Tiwari, A. \& Mehnen, J., 2010. A review of soft computing applications in supply chain management. APPLIED SOFT COMPUTING, 10(3), pp.661-674.

Koerpeoglu, E., Yaman, H., Akturk, M.S., 2011. A multi-stage stochastic programming approach in master production scheduling. EUROPEAN JOURNAL OF OPERATIONAL RESEARCH 213, 166-179.

Koh, S.C.L., Saad, S.M. \& Jones, M.H., 2002. Uncertainty under MRP-planned manufacture: review and categorization. INTERNATIONAL JOURNAL OF PRODUCTION RESEARCH, 40(10), pp.2399-2421.

Kucukyavuz, S., Pochet, Y., 2009. Uncapacitated lot sizing with backlogging: the convex hull. MATHEMATICAL PROGRAMMING 118, 151-175.

Lan, Y., Zhao, R., Tang, W., 2011. Minimum risk criterion for uncertain production planning problems. Computers \& Industrial Engineering 61, 591-599.

Lang, J.C., Domschke, W., 2010. Efficient reformulations for dynamic lot-sizing problems with product substitution. OR SPECTRUM 32, 263-291.

Lang, J.C., Shen, Z.-J.M., 2011. Fix-and-optimize heuristics for capacitated lot-sizing with sequence-dependent setups and substitutions. EUROPEAN JOURNAL OF OPERATIONAL RESEARCH 214, 595-605.

Leung, S., Wu, Y., Lai, K., 2006. A stochastic programming approach for multi-site aggregate production planning. JOURNAL OF THE OPERATIONAL RESEARCH SOCIETY 57, 123-132.

Leung, S.C.H., Chan, S.S.W., 2009. A goal programming model for aggregate production planning with resource utilization constraint. COMPUTERS \& INDUSTRIAL ENGINEERING 56, 1053-1064.

Leung, S.C.H., Lai, K.K., Ng, W.-L., Wu, Y., 2007a. A robust optimization model for production planning of perishable products. JOURNAL OF THE OPERATIONAL RESEARCH SOCIETY 58, 413-422.

Leung, S.C.H., Ng, W.L., 2007a. A stochastic programming model for production planning of perishable products with postponement. Production Planning and Control 18, 190-202. 
Leung, S.C.H., Ng, W.L., 2007b. A goal programming model for production planning of perishable products with postponement. COMPUTERS \& INDUSTRIAL ENGINEERING 53, 531-541.

Leung, S.C.H., Tsang, S.O.S., Ng, W.L., Wu, Y., 2007b. A robust optimization model for multisite production planning problem in an uncertain environment. EUROPEAN JOURNAL OF OPERATIONAL RESEARCH 181, 224-238.

Li, C., Liu, F., Cao, H., Wang, Q., 2009a. A stochastic dynamic programming based model for uncertain production planning of re-manufacturing system. INTERNATIONAL JOURNAL OF PRODUCTION RESEARCH 47, 3657-3668.

Li, H., Meissner, J., 2011. Competition under capacitated dynamic lot-sizing with capacity acquisition. INTERNATIONAL JOURNAL OF PRODUCTION ECONOMICS 131, 535-544.

Li, H., You, T., Luo, X., 2011. Collaborative supply chain planning under dynamic lot sizing costs with capacity decision. JOURNAL OF SYSTEMS ENGINEERING AND ELECTRONICS 22, 247-256.

Li, J., Gonzalez, M., Zhu, Y., 2009b. A hybrid simulation optimization method for production planning of dedicated remanufacturing. INTERNATIONAL JOURNAL OF PRODUCTION ECONOMICS 117, 286-301.

Li, L., Fonseca, D.J., Chen, D.-S., 2006a. Earliness-tardiness production planning for just-intime manufacturing: A unifying approach by goal programming. EUROPEAN JOURNAL OF OPERATIONAL RESEARCH 175, 508-515.

Li, Y., Chen, J., Cai, X., 2006b. Uncapacitated production planning with multiple product types, returned product remanufacturing, and demand substitution. OR SPECTRUM 28, 101125.

Li, Y., Chen, J., Cai, X., 2007. Heuristic genetic algorithm for capacitated production planning problems with batch processing and remanufacturing. INTERNATIONAL JOURNAL OF PRODUCTION ECONOMICS 105, 301-317.

Liang, T.-F., 2007. Application of interactive possibilistic linear programming to aggregate production planning with multiple imprecise objectives. PRODUCTION PLANNING \& CONTROL 18, 548-560.

Liang, T.-F., 2008. Integrating production-transportation planning decision with fuzzy multiple goals in supply chains. INTERNATIONAL JOURNAL OF PRODUCTION RESEARCH 46, 1477-1494.

Lin, J.T., Chen, T.-L., Lin, Y.-T., 2009. Critical material planning for TFT-LCD production industry. INTERNATIONAL JOURNAL OF PRODUCTION ECONOMICS 122, 639655.

Liu, X., Chu, F., Chu, C., Wang, C., 2007. Lot sizing with bounded inventory and lost sales. INTERNATIONAL JOURNAL OF PRODUCTION RESEARCH 45, 5881-5894.

Liu, X., Tu, Y., 2008a. Production planning with limited inventory capacity and allowed stockout. INTERNATIONAL JOURNAL OF PRODUCTION ECONOMICS 111, 180-191.

Liu, X., Tu, Y., 2008b. Capacitated production planning with outsourcing in an OKP company. INTERNATIONAL JOURNAL OF PRODUCTION RESEARCH 46, 5781-5795.

Liu, X., Tu, Y.L., Zhang, J., Watson, L.G., 2008. A genetic algorithm heuristic approach to general outsourcing capacitated production planning problems. INTERNATIONAL JOURNAL OF PRODUCTION RESEARCH 46, 5059-5074.

Lu, L., Qi, X., 2011. Dynamic lot sizing for multiple products with a new joint replenishment model. EUROPEAN JOURNAL OF OPERATIONAL RESEARCH 212, 74-80.

Lukac, Z., Soric, K., Rosenzweig, V.V., 2008. Production planning problem with sequence dependent setups as a bilevel programming problem. EUROPEAN JOURNAL OF OPERATIONAL RESEARCH 187, 1504-1512.

Lusa, A., Corominas, A., Olivella, J., Pastor, R., 2009. Production planning under a working time accounts scheme. INTERNATIONAL JOURNAL OF PRODUCTION RESEARCH 47, 3435-3451. 
Mabert, V.A., 2007. The early road to material requirements planning. Journal of Operations Management 25, 346-356.

Masud, A.S.M., Hwang, C.L., 1980. An aggregate production planning model and application of three multiple objective decision methods $\dagger$. International Journal of Production Research 18, 741-752.

Mateus, G.R., Ravetti, M.G., De Souza, M.C., Valeriano, T.M., 2010. Capacitated lot sizing and sequence dependent setup scheduling: an iterative approach for integration. JOURNAL OF SCHEDULING 13, 245-259.

McDonald, C.M., Karimi, I.A., 1997. Planning and scheduling of parallel semicontinuous processes. 1. Production planning. Industrial \& engineering chemistry research 36, 2691-2700.

Mehrotra, M., Dawande, M., Gavirneni, S., Demirci, M., Tayur, S., 2011. Production Planning with Patterns: A Problem from Processed Food Manufacturing. OPERATIONS RESEARCH 59, 267-282.

Menezes, A.A., Clark, A., Almada-Lobo, B., 2011. Capacitated lot-sizing and scheduling with sequence-dependent, period-overlapping and non-triangular setups. JOURNAL OF SCHEDULING 14, 209-219.

Merzifonluoglu, Y., Geunes, J., 2006. Uncapacitated production and location planning models with demand fulfillment flexibility. INTERNATIONAL JOURNAL OF PRODUCTION ECONOMICS 102, 199-216.

Merzifonluoglu, Y., Geunes, J., Romeijn, H.E., 2007. Integrated capacity, demand, and production planning with subcontracting and overtime options. NAVAL RESEARCH LOGISTICS 54, 433-447.

Min, H., Zhou, G., 2002. Supply chain modeling: past, present and future. COMPUTERS \& INDUSTRIAL ENGINEERING 43(1-2), 231-249.

Mirzapour Al-e-hashem, S.M.J., Malekly, H., Aryanezhad, M.B., 2011. A multi-objective robust optimization model for multi-product multi-site aggregate production planning in a supply chain under uncertainty. International Journal of Production Economics 134, 28-42.

Missbauer, H., Uzsoy, R., 2011. Optimization models of production planning problems. Planning Production and Inventories in the Extended Enterprise 437-507.

Mladenović, N., Hansen, P., 1997. Variable neighborhood search. Computers \& Operations Research 24, 1097-1100.

Mocquillon, C., Lente, C., T’Kindt, V., 2011. An efficient heuristic for medium-term planning in shampoo production. INTERNATIONAL JOURNAL OF PRODUCTION ECONOMICS 129, 178-185.

Mohan, S. et al., 2012. A note on modelling the capacitated lot-sizing problem with set-up carryover and set-up splitting. INTERNATIONAL JOURNAL OF PRODUCTION RESEARCH, 50(19), pp.5538-5543.

Mohebbi, E., Choobineh, F., Pattanayak, A., 2007. Capacity-driven vs. demand-driven material procurement systems. INTERNATIONAL JOURNAL OF PRODUCTION ECONOMICS 107, 451-466.

Moscato, P., 1989. On evolution, search, optimization, genetic algorithms and martial arts: Towards memetic algorithms. Caltech concurrent computation program, C3P Report 826, 1989.

Mula, J., Díaz-Madroñero, M. \& Peidro, D., 2012. A Conceptual Model for Integrating Transport Planning: MRP IV. En J. Frick \& B. T. Laugen, eds. Advances in Production Management Systems. Value Networks: Innovation, Technologies, and Management. IFIP Advances in Information and Communication Technology. Springer Berlin Heidelberg, pp. 54-65.

Mula, J., Peidro, D., Díaz-Madroñero, M., Vicens, E., 2010a. Mathematical programming models for supply chain production and transport planning. European Journal of Operational Research 204, 377-390. 
Mula, J., Peidro, D., Poler, R., 2010b. The effectiveness of a fuzzy mathematical programming approach for supply chain production planning with fuzzy demand. INTERNATIONAL JOURNAL OF PRODUCTION ECONOMICS 128, 136-143.

Mula, J., Poler, R., Garcia-Sabater, J.P., 2008. Capacity and material requirement planning modelling by comparing deterministic and fuzzy models. INTERNATIONAL JOURNAL OF PRODUCTION RESEARCH 46, 5589-5606.

Mula, J., Poler, R., García-Sabater, J.P., Lario, F.C., 2006. Models for production planning under uncertainty: A review. International Journal of Production Economics 103, 271285.

Naeem, M.A., Dias, D.J., Tibrewal, R., Chang, P.C., Tiwari, M.K., 2013. Production planning optimization for manufacturing and remanufacturing system in stochastic environment. JOURNAL OF INTELLIGENT MANUFACTURING, 24(4), pp.717-728.

Nagar, L., Jain, K., 2008. Supply chain planning using multi-stage stochastic programming. SUPPLY CHAIN MANAGEMENT-AN INTERNATIONAL JOURNAL 13, 251-256.

Najid, N.M., Alaoui-Selsouli, M., Mohafid, A., 2011. An integrated production and maintenance planning model with time windows and shortage cost. INTERNATIONAL JOURNAL OF PRODUCTION RESEARCH 49, 2265-2283.

Nascimento, M.C.V., Resende, M.G.C., Toledo, F.M.B., 2010. GRASP heuristic with pathrelinking for the multi-plant capacitated lot sizing problem. EUROPEAN JOURNAL OF OPERATIONAL RESEARCH 200, 747-754.

Nourelfath, M., 2011. Service level robustness in stochastic production planning under random machine breakdowns. EUROPEAN JOURNAL OF OPERATIONAL RESEARCH 212, 81-88.

OGRADY, P., 1982. DETERMINING THE MASTER PRODUCTION SCHEDULE. J. Oper. Res. Soc. 33, 658-658.

Okhrin, I., Richter, K., 2011a. An O(T(3)) algorithm for the capacitated lot sizing problem with minimum order quantities. EUROPEAN JOURNAL OF OPERATIONAL RESEARCH 211, 507-514.

Okhrin, I., Richter, K., 2011b. The linear dynamic lot size problem with minimum order quantity. INTERNATIONAL JOURNAL OF PRODUCTION ECONOMICS 133, 688693.

Omar, M.K., Bennell, J.A., 2009. Revising the master production schedule in a HPP framework context. INTERNATIONAL JOURNAL OF PRODUCTION RESEARCH 47, 58575878.

Omar, M.K., Teo, S.C., 2007. Hierarchical production planning and scheduling in a multiproduct, batch process environment. INTERNATIONAL JOURNAL OF PRODUCTION RESEARCH 45, 1029-1047.

Onal, M., Romeijn, H.E., 2010. Multi-Item Capacitated Lot-Sizing Problems with Setup Times and Pricing Decisions. NAVAL RESEARCH LOGISTICS 57, 172-187.

Ornek, A.M., Cengiz, O., 2006. Capacitated lot sizing with alternative routings and overtime decisions. INTERNATIONAL JOURNAL OF PRODUCTION RESEARCH 44, 53635389.

Ouhimmou, M., D’Amours, S., Beauregard, R., Ait-Kadi, D., Chauhan, S.S., 2008. Furniture supply chain tactical planning optimization using a time decomposition approach. EUROPEAN JOURNAL OF OPERATIONAL RESEARCH 189, 952-970.

Ozturk, C., Ornek, A.M., 2010. Capacitated lot sizing with linked lots for general product structures in job shops. COMPUTERS \& INDUSTRIAL ENGINEERING 58, 151-164.

Pal, A., Chan, F.T.S., Mahanty, B., Tiwari, M.K., 2011. Aggregate procurement, production, and shipment planning decision problem for a three-echelon supply chain using swarmbased heuristics. INTERNATIONAL JOURNAL OF PRODUCTION RESEARCH 49, 2873-2905.

Palaniappan, P.L.K., Jawahar, N., 2011. A genetic algorithm for simultaneous optimisation of lot sizing and scheduling in a flow line assembly. INTERNATIONAL JOURNAL OF PRODUCTION RESEARCH 49, 375-400. 
Pan, Z., Tang, J., Liu, O., 2009. Capacitated dynamic lot sizing problems in closed-loop supply chain. EUROPEAN JOURNAL OF OPERATIONAL RESEARCH 198, 810-821.

Pastor, R., Altimiras, J., Mateo, M., 2009. Planning production using mathematical programming: The case of a woodturning company. COMPUTERS \& OPERATIONS RESEARCH 36, 2173-2178.

Peidro, D., Mula, J., Jimenez, M., Del Mar Botella, M., 2010. A fuzzy linear programming based approach for tactical supply chain planning in an uncertainty environment. EUROPEAN JOURNAL OF OPERATIONAL RESEARCH 205, 65-80.

Peidro, D., Mula, J., Poler, R., Lario, F.-C., 2009. Quantitative models for supply chain planning under uncertainty: a review. Int J Adv Manuf Technol 43, 400-420.

Petrovic, D., Akoez, O., 2008. A fuzzy goal programming approach to integrated loading and scheduling of a batch processing machine. JOURNAL OF THE OPERATIONAL RESEARCH SOCIETY 59, 1211-1219.

Pham, D.T., Ghanbarzadeh, A., Koc, E., Otri, S., Rahim, S., Zaidi, M., 2005. The bees algorithm. Technical note. Manufacturing Engineering Centre, Cardiff University, UK.

Pineyro, P., Viera, O., 2010. The economic lot-sizing problem with remanufacturing and oneway substitution. INTERNATIONAL JOURNAL OF PRODUCTION ECONOMICS 124, 482-488.

Pitakaso, R., Almeder, C., Doerner, K.F., Hartl, R.F., 2006. Combining population-based and exact methods for multi-level capacitated lot-sizing problems. INTERNATIONAL JOURNAL OF PRODUCTION RESEARCH 44, 4755-4771.

Pitakaso, R., Almeder, C., Doerner, K.F., Hartl, R.F., 2007. A MAX-MIN ant system for unconstrained multi-level lot-sizing problems. COMPUTERS \& OPERATIONS RESEARCH 34, 2533-2552.

Pochet, Y., 2001. Mathematical Programming Models and Formulations for Deterministic Production Planning Problems, in: Jünger, M., Naddef, D. (Eds.), Computational Combinatorial Optimization, Lecture Notes in Computer Science. Springer Berlin Heidelberg, pp. 57-111.

Pochet, Y., Wolsey, L.A., 2010. Single item lot-sizing with non-decreasing capacities. MATHEMATICAL PROGRAMMING 121, 123-143.

Qu, X., Williams, J.A.S., 2008. An analytical model for reverse automotive production planning and pricing. EUROPEAN JOURNAL OF OPERATIONAL RESEARCH 190, 756767.

Quadt, D., Kuhn, H., 2007. Capacitated lot-sizing with extensions: a review. 4OR 6, 61-83.

Quadt, D., Kuhn, H., 2008. Capacitated lot-sizing with extensions: a review. 4OR: A Quarterly Journal of Operations Research 6, 61-83.

Quadt, D., Kuhn, H., 2009. Capacitated Lot-Sizing and Scheduling with Parallel Machines, Back-Orders, and Setup Carry-Over. NAVAL RESEARCH LOGISTICS 56, 366-384.

Ram, B., Naghshineh-Pour, M., Yu, X., 2006. Material requirements planning with flexible bills-of-material. INTERNATIONAL JOURNAL OF PRODUCTION RESEARCH 44, 399-415.

Rizk, N., Martel, A., D’Amours, S., 2006a. Multi-item dynamic production-distribution planning in process industries with divergent finishing stages. COMPUTERS \& OPERATIONS RESEARCH 33, 3600-3623.

Rizk, N., Martel, A., D’Amours, S., 2008. Synchronized production-distribution planning in a single-plant multi-destination network. JOURNAL OF THE OPERATIONAL RESEARCH SOCIETY 59, 90-104.

Rizk, N., Martel, A., Ramudhin, A., 2006b. A Lagrangian relaxation algorithm for multi-item lot-sizing problems with joint piecewise linear resource costs. INTERNATIONAL JOURNAL OF PRODUCTION ECONOMICS 102, 344-357.

Roberts, H.J., Barrar, P.R.N., 1992. MRPII implementation: key factors for success. Computer Integrated Manufacturing Systems 5, 31-38.

Romero, D., Vermeulen, D., 2009. Existence of equilibria in a decentralized two-level supply chain. EUROPEAN JOURNAL OF OPERATIONAL RESEARCH 197, 642-658. 
Rong, C., Takahashi, K., Morikawa, K., 2006. MRP rescheduling heuristics with capacity extension under deterministic demand. COMPUTERS \& INDUSTRIAL ENGINEERING 51, 2-13.

Safaei, N., Tavakkoli-Moghaddam, R., 2009. Integrated multi-period cell formation and subcontracting production planning in dynamic cellular manufacturing systems. INTERNATIONAL JOURNAL OF PRODUCTION ECONOMICS 120, 301-314.

Sahinidis, N.V., 2004. Optimization under uncertainty: state-of-the-art and opportunities. Computers \& Chemical Engineering 28, 971-983.

Sahling, F., Buschkuehl, L., Tempelmeier, H., Helber, S., 2009. Solving a multi-level capacitated lot sizing problem with multi-period setup carry-over via a fix-and-optimize heuristic. COMPUTERS \& OPERATIONS RESEARCH 36, 2546-2553.

Salomon, M., Kroon, L.G., Kuik, R., Wassenhove, L.N.V., 1991. Some Extensions of the Discrete Lotsizing and Scheduling Problem. Management Science 37, 801-812.

Santos, M.O., Massago, S., Almada-Lobo, B., 2010. Infeasibility handling in genetic algorithm using nested domains for production planning. COMPUTERS \& OPERATIONS RESEARCH 37, 1113-1122.

Sargut, F.Z., Romeijn, H.E., 2007. Capacitated production and subcontracting in a serial supply chain. IIE TRANSACTIONS 39, 1031-1043.

Schulz, T., 2011. A new Silver-Meal based heuristic for the single-item dynamic lot sizing problem with returns and remanufacturing. INTERNATIONAL JOURNAL OF PRODUCTION RESEARCH 49, 2519-2533.

Schütz, P., Tomasgard, A., 2011. The impact of flexibility on operational supply chain planning. International Journal of Production Economics 134, 300-311.

Selcuk, B., Fransoo, J.C., De Kok, A.G., 2006. The effect of updating lead times on the performance of hierarchical planning systems. INTERNATIONAL JOURNAL OF PRODUCTION ECONOMICS 104, 427-440.

Selcuk, B., Fransoo, J.C., De Kok, A.G., 2008. Work-in-process clearing in supply chain operations planning. IIE TRANSACTIONS 40, 206-220.

Seuring, S., 2013. A review of modeling approaches for sustainable supply chain management. DECISION SUPPORT SYSTEMS 54, 1513-1520.

Shaikh, N., Prabhu, V., Abril, D., Sánchez, D., Arias, J., Rodríguez, E., Riaño, G., 2011. Kimberly-Clark Latin America Builds an Optimization-Based System for Machine Scheduling. Interfaces 41, $455-465$.

Shi, J., Zhang, G., Sha, J., 2011. Optimal production planning for a multi-product closed loop system with uncertain demand and return. COMPUTERS \& OPERATIONS RESEARCH 38, 641-650.

Shi, Y., Eberhart, R., 1998. A modified particle swarm optimizer, in: Evolutionary Computation Proceedings, 1998. IEEE World Congress on Computational Intelligence., The 1998 IEEE International Conference On. IEEE, pp. 69-73.

Shorrock, B., Orlicky, J., 1978. Material Requirements Planning. The Journal of the Operational Research Society 29, 91.

Smith, N.R., Martinez-Flores, J.L., 2007. Discrepancies in solutions between traditional and net present value formulations of finite horizon, discrete-time economic lot size problems. INTERNATIONAL JOURNAL OF PRODUCTION RESEARCH 45, 5731-5741.

Sodhi, M.S., Tang, C.S., 2009. Modeling supply-chain planning under demand uncertainty using stochastic programming: A survey motivated by asset-liability management. INTERNATIONAL JOURNAL OF PRODUCTION ECONOMICS 121, 728-738.

Sridharan, V., Berry, W.L., Udayabhanu, V., 1987. Freezing the Master Production Schedule Under Rolling Planning Horizons. Management Science 33, 1137-1149.

Stadtler, H., 2011. Multi-level single machine lot-sizing and scheduling with zero lead times. EUROPEAN JOURNAL OF OPERATIONAL RESEARCH 209, 241-252.

Stadtler, H. \& Sahling, F., 2013. A lot-sizing and scheduling model for multi-stage flow lines with zero lead times. EUROPEAN JOURNAL OF OPERATIONAL RESEARCH, 225(3), pp.404-419. 
Suerie, C., 2006. Modeling of period overlapping setup times. EUROPEAN JOURNAL OF OPERATIONAL RESEARCH 174, 874-886.

Sun, G., Lee, L.H., Chew, E.P., Shao, J., 2010. A gradient search and column generation approach for the build-pack planning problem with approved vendor matrices and stochastic demand. INTERNATIONAL JOURNAL OF PRODUCTION RESEARCH 48, 5783-5807.

Sundarakani, B., de Souza, R., Goh, M., Wagner, S.M., Manikandan, S., 2010. Modeling carbon footprints across the supply chain. INTERNATIONAL JOURNAL OF PRODUCTION ECONOMICS 128, 43-50.

Sural, H., Denizel, M., Van Wassenhove, L.N., 2009. Lagrangian relaxation based heuristics for lot sizing with setup times. EUROPEAN JOURNAL OF OPERATIONAL RESEARCH 194, 51-63.

Taskin, Z.C., Uenal, A.T., 2009. Tactical level planning in float glass manufacturing with coproduction, random yields and substitutable products. EUROPEAN JOURNAL OF OPERATIONAL RESEARCH 199, 252-261.

Tempelmeier, H., 2007. On the stochastic uncapacitated dynamic single-item lotsizing problem with service level constraints. EUROPEAN JOURNAL OF OPERATIONAL RESEARCH 181, 184-194.

Tempelmeier, H., Buschkuehl, L., 2008. Dynamic multi-machine lotsizing and sequencing with simultaneous scheduling of a common setup resource. INTERNATIONAL JOURNAL OF PRODUCTION ECONOMICS 113, 401-412.

Tempelmeier, H., Buschkuehl, L., 2009. A heuristic for the dynamic multi-level capacitated lotsizing problem with linked lotsizes for general product structures. OR SPECTRUM 31, 385-404.

Tempelmeier, H., Herpers, S., 2011. Dynamic uncapacitated lot sizing with random demand under a fillrate constraint. EUROPEAN JOURNAL OF OPERATIONAL RESEARCH 212, 497-507.

Teunter, R.H., Bayindir, Z.P., Van Den Heuvel, W., 2006. Dynamic lot sizing with product returns and remanufacturing. INTERNATIONAL JOURNAL OF PRODUCTION RESEARCH 44, 4377-4400.

Tian, F., Willems, S.P., Kempf, K.G., 2011. An iterative approach to item-level tactical production and inventory planning. INTERNATIONAL JOURNAL OF PRODUCTION ECONOMICS 133, 439-450.

Timm, T., Blecken, A., 2011. A method for the hierarchical planning of the structure, dimension and material requirements of manufacturing systems. INTERNATIONAL JOURNAL OF PRODUCTION RESEARCH 49, 3431-3453.

Toledo, C.F.M., Franca, P.M., Morabito, R., Kimms, A., 2009. Multi-population genetic algorithm to solve the synchronized and integrated two-level lot sizing and scheduling problem. INTERNATIONAL JOURNAL OF PRODUCTION RESEARCH 47, 30973119.

Toledo, F.M.B., Armentano, V.A., 2006. A Lagrangian-based heuristic for the capacitated lotsizing problem in parallel machines. EUROPEAN JOURNAL OF OPERATIONAL RESEARCH 175, 1070-1083.

Tonaki, V.S., Toledo, F.M.B., 2010. An approach for solving the lot-sizing problem of a market-driven foundry. JOURNAL OF THE OPERATIONAL RESEARCH SOCIETY $61,108-114$.

Torabi, S.A., Hassini, E., 2009. Multi-site production planning integrating procurement and distribution plans in multi-echelon supply chains: an interactive fuzzy goal programming approach. INTERNATIONAL JOURNAL OF PRODUCTION RESEARCH 47, 5475-5499.

Toso, E.A.V., Morabito, R., Clark, A.R., 2009. Lot sizing and sequencing optimisation at an animal-feed plant. COMPUTERS \& INDUSTRIAL ENGINEERING 57, 813-821.

Transchel, S., Minner, S., Kallrath, J., Loehndorf, N., Eberhard, U., 2011. A hybrid general lotsizing and scheduling formulation for a production process with a two-stage product 
structure. INTERNATIONAL JOURNAL OF PRODUCTION RESEARCH 49, 24632480.

Van den broecke, F., Van Landeghem, H., Aghezzaf, E.-H., 2008. Implementing a near-optimal solution for the multi-stage, multi-product capacitated lot-sizing problem by rolling out a cyclical production plan. INTERNATIONAL JOURNAL OF PRODUCTION ECONOMICS 112, 121-137.

Van den Heuvel, W., Borm, P., Hamers, H., 2007. Economic lot-sizing games. EUROPEAN JOURNAL OF OPERATIONAL RESEARCH 176, 1117-1130.

Van den Heuvel, W., Wagelmans, A., 2006. A polynomial time algorithm for a deterministic joint pricing and inventory model. EUROPEAN JOURNAL OF OPERATIONAL RESEARCH 170, 463-480.

Van Vyve, M., 2006. Linear-programming extended formulations for the single-item lot-sizing problem with backlogging and constant capacity. MATHEMATICAL PROGRAMMING 108, 53-77.

Van Vyve, M., Wolsey, L., 2006. Approximate extended formulations. MATHEMATICAL PROGRAMMING 105, 501-522.

Verdegay, J.L., Yager, R.R., Bonissone, P.P., 2008. On heuristics as a fundamental constituent of soft computing. Fuzzy Sets and Systems 159, 846-855.

Voss, S., Osman, I.H., Roucairol, C. (Eds.), 1999. Meta-Heuristics: Advances and Trends in Local Search Paradigms for Optimization. Kluwer Academic Publishers, Norwell, MA, USA.

Wei, C., Li, Y., Cai, X., 2011. Robust optimal policies of production and inventory with uncertain returns and demand. International Journal of Production Economics 134, 357367.

Whybark, D.C., Williams, J.G., 1976. Material Requirements Planning Under Uncertainty. Decision Sciences 7, 595-606.

Wolsey, L., 2006. Lot-sizing with production and delivery time windows. MATHEMATICAL PROGRAMMING 107, 471-489.

Wong, B.K., Lai, V.S., 2011. A survey of the application of fuzzy set theory in production and operations management: 1998-2009. International Journal of Production Economics 129, 157-168.

Wu, C.-H., Lin, J.T., Wu, H.-H., 2010. Robust production and transportation planning in thin film transistor-liquid crystal display (TFT-LCD) industry under demand and price uncertainties. INTERNATIONAL JOURNAL OF PRODUCTION RESEARCH 48, 6037-6060.

Wu, M.-C., Huang, L.-C., Hsu, H.-M., Su, T.-S., 2011a. Multiple lot-sizing decisions in a twostage production with an interrupted geometric yield and non-rigid demand. JOURNAL OF THE OPERATIONAL RESEARCH SOCIETY 62, 1075-1084.

Wu, T., Shi, L., Geunes, J., Akartunali, K., 2011b. An optimization framework for solving capacitated multi-level lot-sizing problems with backlogging. EUROPEAN JOURNAL OF OPERATIONAL RESEARCH 214, 428-441.

Wu, Y., 2011. A stochastic model for production loading in a global apparel manufacturing company under uncertainty. PRODUCTION PLANNING \& CONTROL 22, 269-281.

Xiao, Y., Kaku, I., Zhao, Q., Zhang, R., 2011a. A variable neighborhood search based approach for uncapacitated multilevel lot-sizing problems. COMPUTERS \& INDUSTRIAL ENGINEERING 60, 218-227.

Xiao, Y., Kaku, I., Zhao, Q., Zhang, R., 2011b. A reduced variable neighborhood search algorithm for uncapacitated multilevel lot-sizing problems. EUROPEAN JOURNAL OF OPERATIONAL RESEARCH 214, 223-231.

Xue, G., Offodile, O.F., Zhou, H., Troutt, M.D., 2011. Integrated production planning with sequence-dependent family setup times. INTERNATIONAL JOURNAL OF PRODUCTION ECONOMICS 131, 674-681.

Yang, J., Qi, X., 2010. Managing partially controllable raw material acquisition and outsourcing in production planning. IIE TRANSACTIONS 42, 188-202. 
Yang, S., Yang, J. \& Abdel-Malek, L., 2007. Sourcing with random yields and stochastic demand: A newsvendor approach. COMPUTERS \& OPERATIONS RESEARCH, 34(12), pp.3682-3690.

Yimer, A.D., Demirli, K., 2010. A genetic approach to two-phase optimization of dynamic supply chain scheduling. COMPUTERS \& INDUSTRIAL ENGINEERING 58, 411422.

Zanjani, M.K., Ait-Kadi, D., Nourelfath, M., 2010a. Robust production planning in a manufacturing environment with random yield: A case in sawmill production planning. EUROPEAN JOURNAL OF OPERATIONAL RESEARCH 201, 882-891.

Zanjani, M.K., Nourelfath, M., Ait-Kadi, D., 2010b. A multi-stage stochastic programming approach for production planning with uncertainty in the quality of raw materials and demand. INTERNATIONAL JOURNAL OF PRODUCTION RESEARCH 48, 47014723.

Zanjani, M.K., Nourelfath, M., Ait-Kadi, D., 2011. Production planning with uncertainty in the quality of raw materials: a case in sawmills. JOURNAL OF THE OPERATIONAL RESEARCH SOCIETY 62, 1334-1343.

Zhang, Z.-H., Jiang, H. \& Pan, X., 2012. A Lagrangian relaxation based approach for the capacitated lot sizing problem in closed-loop supply chain. INTERNATIONAL JOURNAL OF PRODUCTION ECONOMICS, 140(1), pp.249-255.

Zhang, G., Shang, J., Li, W., 2011. Collaborative production planning of supply chain under price and demand uncertainty. EUROPEAN JOURNAL OF OPERATIONAL RESEARCH 215, 590-603.

Zolghadri, M., Olivier, C., Bourrieres, J.-P., 2008. Close-optimal production and procurement policy for a X-network of added value using lexicographic linear goal programming. COMPUTERS \& INDUSTRIAL ENGINEERING 54, 821-839. 